\title{
Morfología de cráteres de impacto en áreas pantanosas
}

\author{
J.-Valentín Mauri ${ }^{1, *}$ \\ ${ }^{1}$ Máster, Departamento de Astronomía y Astrofísica de la UNAH \\ DOI: https://doi.org/10.5377/ce.v11i2.8675
}

\begin{abstract}
RESUMEN
Durante un evento de impacto, a medida que se transfiere la energía, se forma un cráter cuyas características dependen no solo de la cantidad de energía del proyectil, sino también de la composición y naturaleza de los materiales de la superficie. Esta investigación se basa en la simulación de impactos en un material seleccionado, saturado con agua, con el objetivo de obtener la morfología general de cráteres de impacto en áreas pantanosas y la caracterización de la dispersión del eyecta. Con el fin de establecer una plantilla general que sirva de apoyo a la identificación de posibles candidatos a cráter de impacto, en pantanos o humedales del planeta Tierra, Marte y otros cuerpos rocosos ricos en elementos volátiles. Se utilizó un dispositivo de simulación con una configuración que permite variar el ángulo de disparo sin variar la distancia al objetivo. Para la simulación de impactos se utilizó un rifle de aire comprimido calibre 22 que dispara perdigones de plomo a una velocidad de $304.8 \mathrm{~m} / \mathrm{s}$. Se observó una disminución del diámetro del cráter según se aumentaba el ángulo de incidencia. Las características más notables del eyecta son los lóbulos unidos al borde principal y los segmentos discretos que se desprenden del borde para formar promontorios. Se cotejó que el borde sur (dirección de entrada del proyectil) siempre es más estrecho que el borde norte (dirección opuesta de entrada del proyectil). Esta característica junto con la medida del eje mayor de la forma elíptica del cráter se puede utilizar como indicador de la dirección de entrada del impactor.
\end{abstract}

Palabras clave: craterización por impacto, morfología de cráteres, pantanos, humedales.

\begin{abstract}
During an impact event, as the energy is transferred, a crater is formed whose characteristics depend not only on the amount of energy of the projectile, but also on the composition and nature of the surface materials. This research is based on the simulation of impacts on a selected material, saturated with water, with the aim of obtaining the general morphology of impact craters in marshy areas and the characterization of the ejecta dispersion. In order to establish a general template to support the identification of potential candidates for impact crater, in marshes or wetlands of the planet Earth, Mars and other rocky bodies rich in volatiles. A simulation device with a configuration that allows to vary the firing angle without varying the distance to the target was used. For the impact simulation, a 22-gauge air rifle was used to fire lead pellets at a rate of $304.8 \mathrm{~m} / \mathrm{s}$. A decrease in the diameter of the crater was observed as the angle of incidence was increased. The most notable features of the ejecta are the lobes attached to the main edge and the discrete segments that detach from the edge to form promontories. It was checked that the southern edge is always narrower than the northern edge. This feature together with the measurement of the major axis of the elliptical shape of the crater can be used as an indicator of the direction of entry of the impactor.
\end{abstract}

Keywords: impact cratering, crater morphology, swamps, wetlands.

*jose.mauri@unah.edu.hn 


\section{Introducción}

La formación de cráteres de impacto es el resultado de la transferencia de la energía cinética de un proyectil a la superficie de un planeta. A medida que se transfiere la energía se forma un cráter cuyas características dependen no solo de la cantidad de energía que tiene el proyectil, sino también de la composición y naturaleza de los materiales de la superficie. Como resultado, los cráteres de impacto no se ven todos iguales; los grandes cráteres son claramente diferentes de los pequeños cráteres en su geometría general. Los pequeños cráteres son como un tazón con paredes y suelos lisos; cráteres más grandes y complejos desarrollan paredes escalonadas y picos centrales; y cuencas aún más grandes desarrollan múltiples anillos concéntricos. Los cambios morfológicos que acompañan a los cambios en el tamaño del cráter son reflejo de la cantidad de energía gastada por un proyectil cuando colisiona con la superficie de un planeta, energía que es proporcional a la masa y velocidad del proyectil que cae (Christiansen y Spilker, 2017).

La morfología general de los cráteres de impacto más habituales, los pequeños y medianos, no viene muy condicionada por el tipo de roca impactada, aunque los cráteres en rocas sedimentarias poco cohesionadas tienden a colapsarse más fácilmente que si se trata de rocas cristalinas muy consolidadas. Sin embargo, las estructuras preexistentes en la roca impactada pueden influir en gran medida en la forma del cráter (Ormö y Oms, 2013). Un ejemplo de esto es el cráter Barringer (Meteor Crater). (Perumal y Kring, 2008) llegan a la conclusión de que una combinación de fallas a lo largo de juntas orientadas en diagonal y el "movimiento controlado por fractura" a lo largo de las paredes del cráter condujo a la forma cuadrada del cráter.

Si el sitio de impacto original está cubierto por agua, lo que se conoce como impactos marinos, la formación y la evolución posterior del cráter resultante pueden ser más complejos. En el momento del impacto, la capa de agua que la recubre se excavará con el lecho de roca subyacente, y el desarrollo del cráter y la deposición de las unidades rocosas producidas por el impacto se verán modificados por el resurgimiento inmediato y violento del agua hacia la cavidad del cráter (Therriault y Lindström, 1995), (Lindström et al., 1996).

¿Pero qué hay de los impactos y la morfología de cráteres en zonas palustres? Donde el material objetivo está condicionado por depósitos aluviales formados por la acumulación de materia orgánica casi exclusivamente de origen vegetal, además de grava, arena, arcilla y limos. Donde el nivel del agua se mantiene relativamente al nivel de la superficie del humedal.

En el presente proyecto de investigación se recreó un evento de impacto de asteroide sobre un área pantanosa mediante una simulación de laboratorio que consistió en el disparo de proyectiles sobre material de diferente clasificación granulométrica, contenido en una mesa metálica similar a una mesa de cultivo que está dentro de una cámara de seguridad.

El material saturado de agua y emplazado en 2 capas, de forma que se puedan recrear las condiciones de sedimentación de un pantano real. El espesor de las diferentes capas de material se situó de acuerdo con el registro estratigráfico del pantano de la Mosquitia, formado por sedimentos fluviales que se depositaron durante un periodo de tiempo geológico reciente.

El diámetro límite de experimentación es análogo a un cráter de $3.2-4.2 \mathrm{~km}$ en la Tierra, que está en el rango de clasificación de un cráter simple (Dence, 1965).

El disparo de proyectiles se efectuó con un rifle de aire comprimido calibre 22, desde una misma distancia, pero con ángulos que van desde 45 a 90 grados (Collins et al., 2005). El ángulo de impacto más probable es $45^{\circ}$ (Shoemaker, 1962). 
Las dimensiones de la mesa metálica son de $60 \mathrm{~cm} \times 60 \mathrm{~cm}$, con una profundidad de $25 \mathrm{~cm}$, sobre una plataforma nivelable de $40 \mathrm{~cm}$ de altura. Dos barras paralelas en cada extremo de la mesa y unidas entre sí, permiten cambiar el ángulo de disparo.

Se ejecutaron disparos con una diferencia de 5 grados cada uno, los cuales se captaron por una cámara de filmación. Después de cada disparo se midió la altura del borde del cráter, la profundidad del cráter y se describieron las características del eyecta. Los eyecta de impacto constituyen un grupo especial de sedimentos que comprenden aquellos materiales que son expulsados del cráter de impacto durante el estadio de excavación y que son depositados a su alrededor. Los eyecta de impacto son por lo general extremadamente heterogéneos debido a las condiciones del objetivo (p.e., continental o marino), la litoestratigrafía del objetivo (de naturaleza cristalina, sedimentaria o mixta), los complejos procesos de excavación, el complejo aterrizaje de los eyecta y los procesos de emplazamiento. Este último incluye la craterización secundaria y la mezcla con material local (Ernstson y Claudin, 2018).

Con los datos obtenidos se procedió a analizar la información, con el objetivo de definir una morfología general de un cráter de impacto en terrenos con las características antes mencionadas. Se realizó una discusión de los resultados usando geología comparativa con el pantano de la Mosquitia (Laguna Liwa), donde encontramos una estructura circular típica de un cráter de impacto. Comparaciones llevadas a cabo desde una perspectiva de carácter exploratorio. Se finaliza con las recomendaciones y conclusiones. El enfoque del problema se efectuó desde dos puntos de vista: 1) experimentos de laboratorio usando un dispositivo de simulación, y 2) el uso de la fotogeología que nos proporcione una base de comparación para los resultados de laboratorio.

Estos experimentos no solamente pueden aplicarse a los cráteres de impacto en Marte y la Tierra, sino que pueden tener implicaciones en la craterización de los satélites de los planetas exteriores ricos en elementos volátiles, así como también en la mejor comprensión de los procesos generales del craterismo de impacto (Greeley et al., 1980).

El propósito fundamental es determinar el efecto de un impacto de asteroide en un suelo saturado con agua (material viscoso), tanto en la morfología del cráter como en la dispersión del eyecta, en comparación a la morfología de cráteres observados en objetivos "secos" y rocosos.

Se determinó una morfología de cráteres de impacto en áreas pantanosas, así como la caracterización de la dispersión del eyecta, con el propósito de establecer una plantilla general que sirva de apoyo a la identificación de cuerpos geológicos, posibles candidatos a cráter de impacto, en pantanos o humedales del planeta Tierra y otros cuerpos rocosos.

Con el uso de la geología comparativa podemos emplear dicha plantilla general en cráteres del planeta Marte que muestran mantos de eyección que poseen una morfología "fluidizada" única, que se ha atribuido a la influencia del agua subterránea o de hielo dentro del material objetivo al momento de formación del cráter (Head y Roth, 1976), (Carr et al., 1977).

\section{Metodología}

El proceso de formación de cráteres se puede comparar con una explosión, con algunas diferencias importantes con respecto a la explosión, como problemas de escala, falta de momentum del proyectil y expansión de gas en lugar de excavación impulsada por golpes (Melosh, 1989). También hay diferencias 
entre los cráteres de impacto a hipervelocidad y el empuje mecánico del proyectil en impactos de baja velocidad (Ormö et al., 2006). Esto conduce a diferentes relaciones entre las propiedades del impactor y los cráteres resultantes. En este estudio interesan ciertos aspectos de la formación de cráteres de impacto que no se ven afectados significativamente por las diferencias de escala. Por ejemplo, por la velocidad y densidad del impactor.

Los experimentos de impacto se llevaron a cabo en septiembre, octubre y noviembre del año 2017, utilizando el dispositivo de simulación, donde se llevaron a cabo los disparos sobre un material saturado de agua. Tanto el material utilizado como el dispositivo de simulación se describen en las siguientes secciones.

Para documentar los disparos se utilizó una cámara digital Canon Rebel de 25 cuadros por segundo. Para los disparos se utilizó un rifle de aire comprimido calibre 22 con la capacidad de disparar perdigones a 1000 pies/seg usando perdigones de plomo y 1200 pies/seg con perdigones de aluminio. Para este experimento se utilizaron perdigones de plomo de 14.3 gramos de masa, con lo cual se obtiene una energía cinética máxima de aproximadamente 43.04 Joule. La velocidad de disparo del rifle es 36.18 veces menor que la mínima velocidad de impacto de $11 \mathrm{~km} / \mathrm{s}$, la velocidad de escape de la Tierra.

El propósito del experimento fue poder generar cráteres que permitan el estudio tanto del comportamiento del eyecta (eyecta que consiste en material saturado y cohesionado por el agua) como del borde y la cavidad del cráter debido al posible resurgimiento del agua. Es decir, el análisis de un evento de impacto durante las etapas de excavación y modificación en un material saturado con agua.

Se usó el software Civil 3D de Autocad 2015 para escalar las imágenes y hacer dibujos sobre estas. El Autocad permite obtener áreas de zonas delimitadas por líneas, además permite corroborar la medición del diámetro del cráter y si este es circular o de forma elíptica. Asimismo permite hacer un conteo de los promontorios y cráteres secundarios.

\subsection{Dispositivo de simulación}

El dispositivo de simulación consiste en un recipiente tipo mesa, fabricado de láminas y ángulos de hierro que está dentro de una cámara de seguridad. Las dimensiones de la mesa metálica son de $60 \times 60 \mathrm{~cm}$ con una profundidad de $25 \mathrm{~cm}$, sobre cuatro patas extensibles de $40 \mathrm{~cm}$ de altura inicial, que están ancladas al suelo con concreto. Dos tubos de $1^{\prime \prime}$ de diámetro y de $5 \mathrm{~cm}$ de largo se soldaron a ambos costados y al centro de la mesa. Dos tubos soldados en forma de "L" encajan en los dos tubos cortos (ver figura 1). Los tubos en forma de "L" están unidos por una platina y un tubo del mismo diámetro en forma transversal. Esta disposición permite que los tubos en forman de "L" se muevan de forma circular en torno a un eje formado por los dos tubos cortos de $5 \mathrm{~cm}$. Esta configuración permite variar el ángulo de disparo sin variar la distancia al objetivo. Para la simulación de impactos se utilizó un rifle de aire comprimido calibre 22 que dispara perdigones de plomo a una velocidad de 1000 pies $/ \mathrm{seg}(304.8 \mathrm{~m} / \mathrm{s})$. 

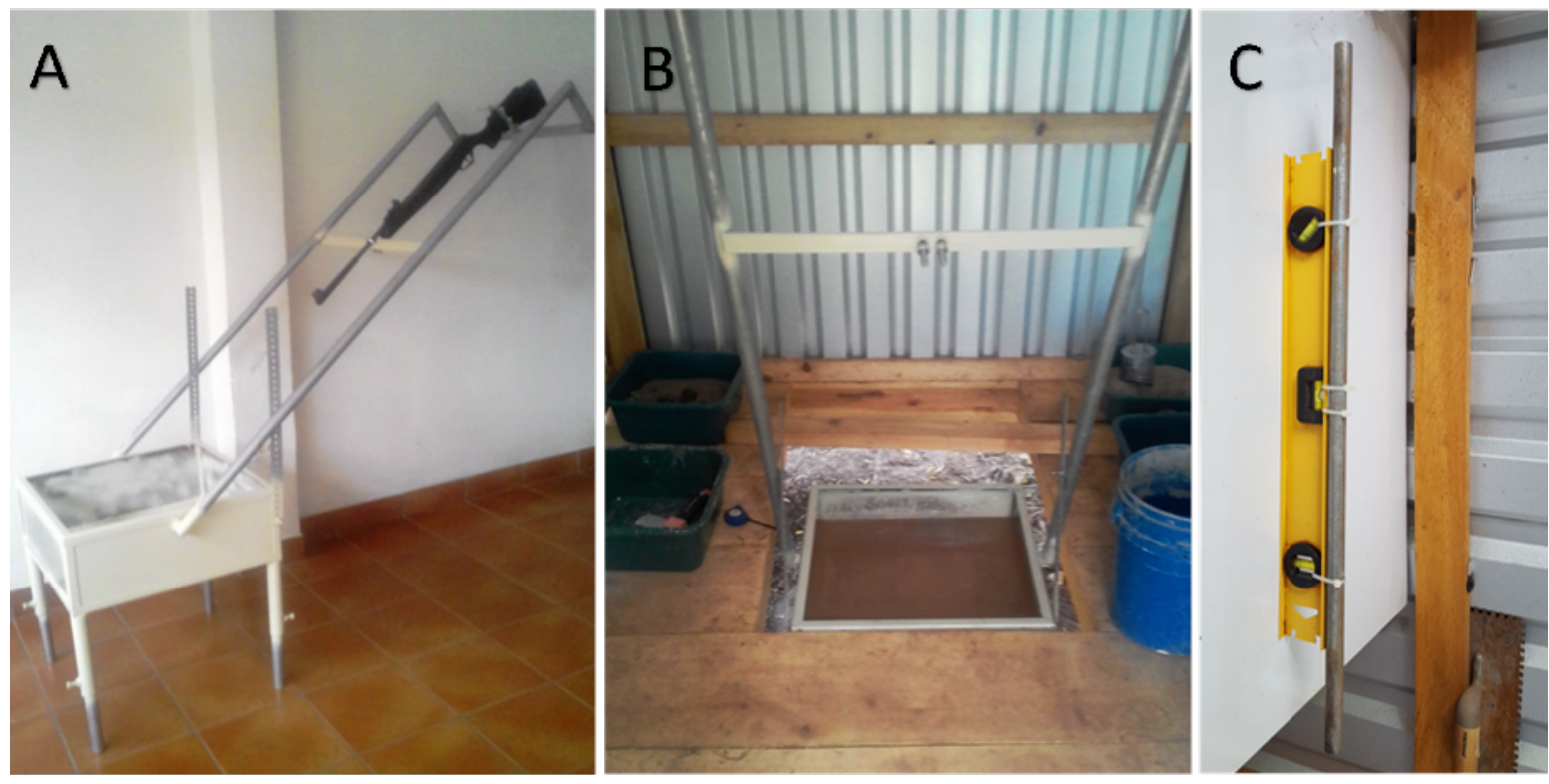

Figura 1: Dispositivo de simulación. A) Rifle acoplado a $45^{\circ}$. Los tubos plateados de las patas extensibles quedaron embebidos en concreto. B) Dispositivo de simulación instalado en la caseta de seguridad con el borde superior de la mesa al mismo nivel del suelo de la cámara. C) Nivel para allanar el material. Fotografías propias.

\subsection{Características y configuración del material objetivo}

Después de realizar simulaciones con diferentes materiales saturados de agua, i.e, con arenilla blanca tamizada, tierra negra tamizada, tierra roja tamizada y una mezcla de los tres materiales que consiste en: una parte de arenilla, una parte de tierra negra y cinco partes de tierra roja, la cual se batió hasta obtener una pasta homogénea, se determinó que con la mezcla de los tres materiales se obtienen mayores diámetros y eyectas más pronunciadas. Por lo que se decidió utilizar esta combinación de materiales como el "material objetivo" para llevar a cabo el experimento. Se ha denominado norte del cráter a la dirección opuesta de entrada del proyectil. El sur del cráter es exactamente la dirección de entrada del proyectil.

La configuración de los materiales para la simulación de impactos utilizada en todos los disparos a diferentes ángulos se describe a continuación:

- Sobre el fondo de la mesa metálica, una capa de $12 \mathrm{~cm}$ de gravín. El material y los espacios vacíos quedan saturados de agua para impedir la absorción de agua del material suprayacente.

- Encima del gravín se coloca una capa de $5 \mathrm{~cm}$ de arenilla fina y colada que es saturada con agua. Por último, se coloca una capa de $5 \mathrm{~cm}$ de material objetivo saturado de agua, el cual se allana con un nivel de burbuja adherido a un tubo de $1 / 2$ pulgada de diámetro (ver figura 1c). El nivel adherido al tubo permite dejar el material objetivo siempre a la misma elevación, con el propósito de no variar la distancia de la boca del cañón al material objetivo durante todos los disparos.

- Después de nivelar cuidadosamente el material objetivo se agrega agua con una jeringa de $10 \mathrm{ml}$ para no dañar la superficie lisa hasta obtener un nivel de $5 \mathrm{~mm}$ de agua sobre el nivel del material objetivo.

- Se deja reposar el material objetivo saturado durante 24 horas para simular las condiciones de sedimentación y compactación que ocurren en un pantano real. 
- Después de las 24 horas de reposo se extrae el exceso de agua con jeringa para dejar el nivel de agua a una elevación aproximada de $1 \mathrm{~mm}$ sobre el nivel del material objetivo. Inmediatamente se procede a efectuar el disparo a los diferentes ángulos propuestos para luego tomar datos del diámetro del cráter, altura del borde, profundidad del cráter y descripción del eyecta, resultado de solamente variar el ángulo de incidencia.

\section{Resultados}
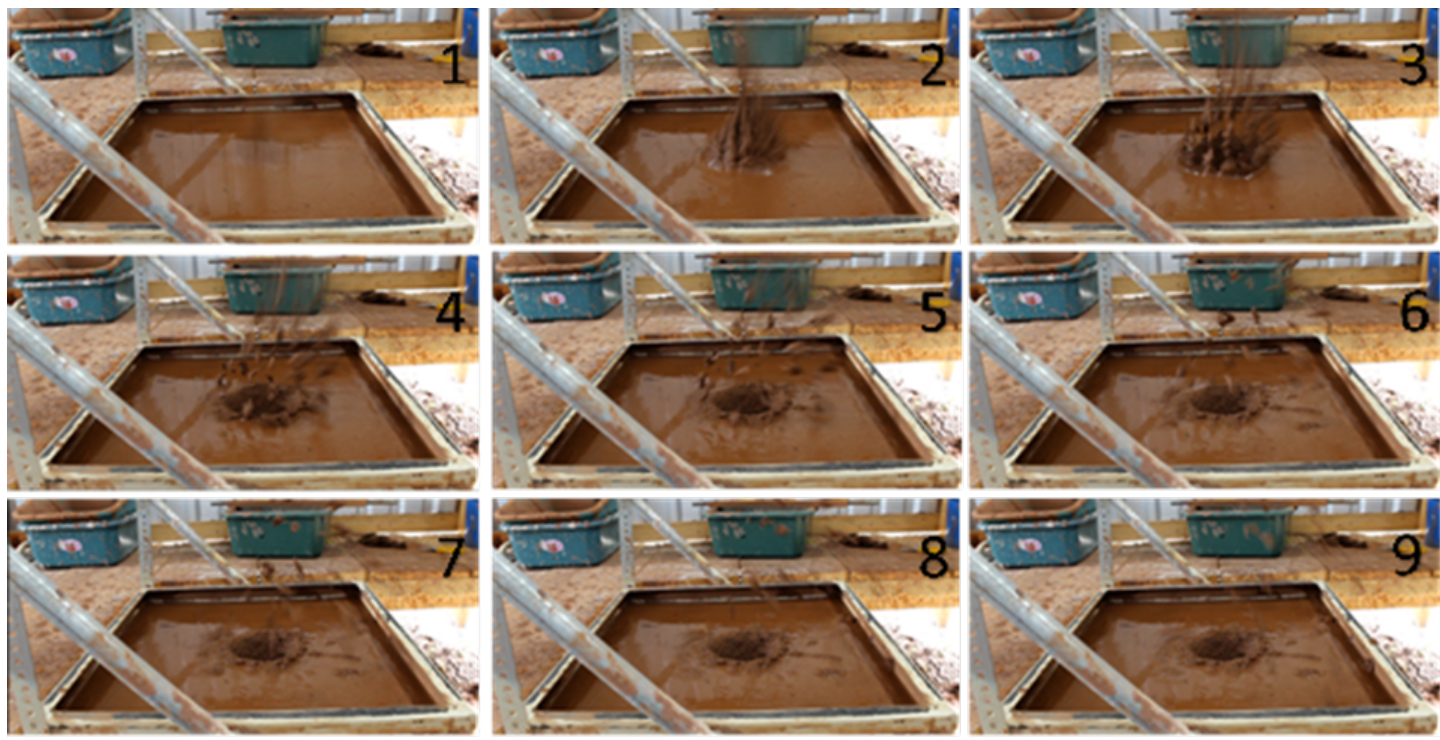

Figura 2: Secuencia del experimento de impacto utilizando ángulo de incidencia de $45^{\circ}$

En la figura 2 se observa la secuencia del disparo con ángulo de incidencia de $45^{\circ}$. Cuadro 1: una fracción de segundo después de la fase de contacto y compresión, la energía cinética del proyectil se transfiere al material objetivo mediante ondas de choque, dando inmediatamente inicio a la fase de excavación. Cuadro 2: El material del nivel superior central es expulsado en forma de una pluma delgada y fluida a gran velocidad, a un ángulo de $90^{\circ}$ de la superficie. Otras plumas de menor longitud en la periferia del centro se expanden hacia arriba y afuera a diferentes ángulos mientras el cráter comienza a expandirse. De las diferentes plumas que se forman, se puede visualizar que aún siguen unidas a la superficie. Cuadros 3, 4, 5 y 6: las diferentes plumas expansivas se rompen en segmentos discretos cuando los esfuerzos tensiónales exceden la cohesión del material. Estos fragmentos o grumos comienzan a desplazarse preferentemente en dirección norte del cráter (periferia correspondiente a cuadrantes 1 y 4). En el cuadro 4 se observa como el material más alejado del punto central de impacto que no logra desprenderse de la superficie se dobla hacia afuera y comienza a formar el borde. Cuadros 7, 8 y 9: después de alcanzar su máxima altura los grumos comienzan su descenso hasta impactar con la superficie indemne para formar cráteres secundarios de diversos tamaños. Asimismo, los grumos que viajan con ángulos oblicuos y a menores velocidades forman promontorios aislados de distintas morfologías y tamaños, los cuales obtienen y conservan una mayor elevación al resto de la superficie de material inalterado. En la tabla 1 se muestra el resultado de la medición de los cráteres que se formaron al variar el ángulo de incidencia en el transcurso del experimento. 
Dimensión de los componentes del cráter resultado de variar el ángulo de incidencia

\begin{tabular}{cccccc}
\hline $\begin{array}{c}\text { Ángulo de Incidencia } \\
(\circ)\end{array}$ & $\begin{array}{c}\text { Diámetro N-S } \\
(\mathrm{mm})\end{array}$ & $\begin{array}{c}\text { Profundidad del cráter } \\
(\mathrm{mm})\end{array}$ & $\begin{array}{c}\text { Altura del borde } \\
\text { promedio }(\mathrm{mm})\end{array}$ & $\begin{array}{c}\text { Área del borde, cuadrantes } \\
1 \mathrm{y} 4\left(\mathrm{~cm}^{2}\right) \text { figura 3 }\end{array}$ & $\begin{array}{c}\text { Área del borde, cuadrantes } \\
2 \mathrm{y} 3\left(\mathrm{~cm}^{2}\right) \text { figura 3 }\end{array}$ \\
\hline $45^{\circ}$ & 145.0 & 53.0 & 9.5 & 61.47 & 47.32 \\
$50^{\circ}$ & 140.0 & 53.0 & 7.75 & 59.56 & 43.29 \\
$55^{\circ}$ & 130.0 & 58.0 & 9.5 & 59.07 & 25.67 \\
$60^{\circ}$ & 118.0 & 60.0 & 9.25 & 15.93 & 5.95 \\
$65^{\circ}$ & 73.0 & 27.0 & 6.00 & 9.13 & 9.96 \\
$70^{\circ}$ & 70.0 & 41.0 & 7.5 & 5.04 & 0.22 \\
$75^{\circ}$ & 67.40 & 42.0 & 3.0 & 4.13 & 0.0 \\
$80^{\circ}$ & 60.0 & 20.0 & 2.13 & 0.0 & 0.0 \\
$85^{\circ}$ & 50.0 & 18.0 & 0.0 & 0.0 & 0.0 \\
$90^{\circ}$ & 46.0 & 18.0 & 1.13 & & \\
\hline
\end{tabular}

Tabla 1: Medición de los componentes del cráter, según el ángulo de incidencia. Medidas en milímetros (mm) y áreas en centímetros cuadrados $\left(\mathrm{cm}^{2}\right)$. Ver figura 3 en el anexo a tabla 1.
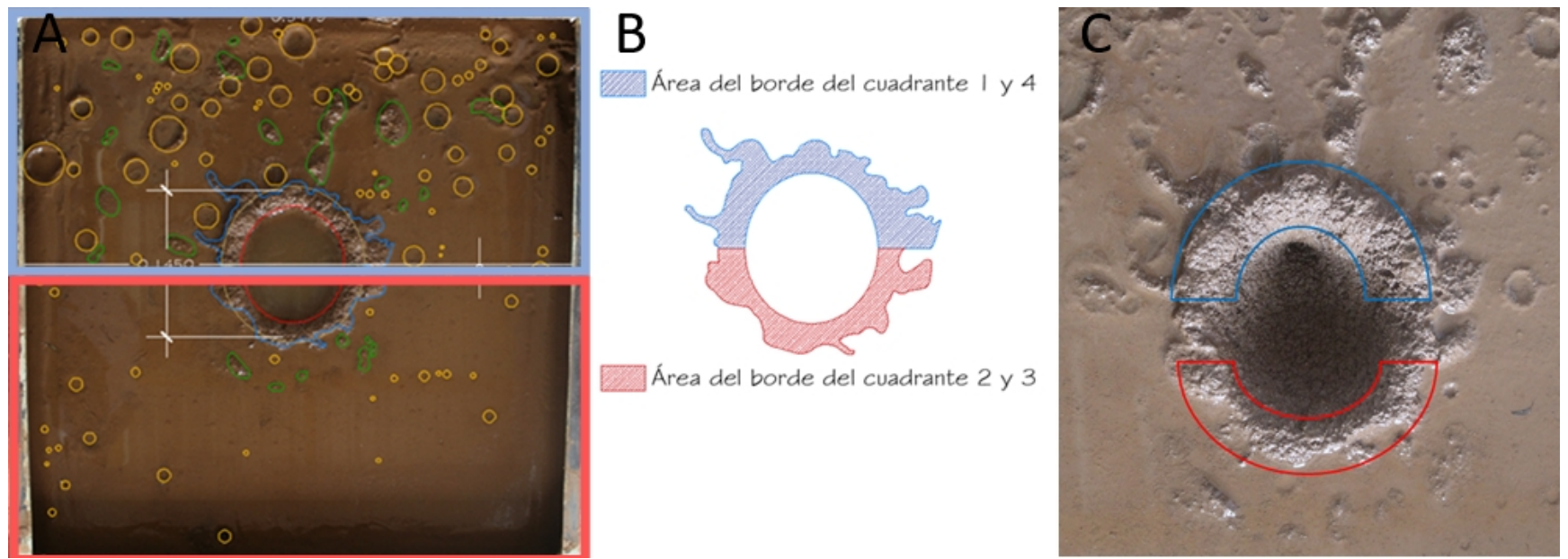

Figura 3: Experimento de impacto con ángulo de incidencia de $45^{\circ}$. A) El cuadro azul es el cuadrante 1 y 4 , el cuadro rojo el cuadrante 2 y 3. B) Área sombreada en azul corresponde al borde norte y área sombreada en rojo al borde sur. C) Delineado en rojo se observa el borde sur que es más angosto que el borde norte delineado en azul. Imágenes propias y áreas obtenidas con ayuda del software Autocad (C)

\section{Discusión}

A pesar de las limitaciones de este experimento, fue posible observar las características del eyecta que se producen cuando el agua satura el material objetivo. La limitación más importante fue la baja velocidad del impactor, lo que se traduce en menor energía cinética. La reducción de la energía cinética de la componente norte (eje $x$ ) conforme se incrementaba el ángulo de incidencia produjo cráteres con bordes cada vez menos elevados y completos (ver figura 4).

Durante la etapa de contacto y compresión, la energía cinética del proyectil se transfiere al material objetivo por medio de ondas de choque generadas durante la interacción entre el proyectil y la superficie. Las características generales de esta conversión de energía cinética en ondas de choque se han determinado a partir de experimentos y estudios teóricos (Okeefe y Ahrens, 1975), (Okeefe y Ahrens, 1977), (Okeefe y Ahrens, 1992), (Ahrens y Okeefe, 1977), (Roddy et al., 1977), (Melosh, 1989). Las ondas de choque se propagan tanto al material impactado como hacia la parte trasera del proyectil.

En este experimento la presión de las "ondas de choque" no es lo suficientemente grande como para llamarlas así. En el 2006, Örmo las llamó ondas de estrés mecánico. La propagación de esta onda de 
estrés a través del material objetivo saturado causa la salida de una pluma (chorro o jet) de material aún aglutinado por las fuerzas de cohesión y adhesión que ejerce el agua sobre el material objetivo, en los primeros instantes, perpendicular a la superficie. Durante la etapa de excavación, un décimo de segundo después aproximadamente, el material inmediatamente inferior a la superficie de contacto comienza su emplazamiento a diferentes ángulos y preponderantemente en dirección norte. Esta pluma de material empieza a separarse en segmentos discretos cuando los esfuerzos tensiónales exceden la cohesión del material. Otras plumas de menor longitud en la periferia del centro se expanden hacia arriba y afuera a diferentes ángulos mientras el cráter se expande hasta alcanzar lo que se conoce como cráter transitorio. Durante el mismo instante, la componente norte (ver figura 4) de la energía cinética total, produce un frente de choque que se expande de forma radial y en oposición al punto norte. La expansión de las ondas que produce el frente de choque, primero; da paso a la formación del borde norte volcando el material hacia afuera. Parte del material que no logra quedar adherido al borde se desprende para caer a la superficie y produce promontorios aislados. Segundo; el material que comenzó su vuelco para formar el borde en el punto norte del cráter sigue su apertura en oposición a este, siguiendo una dirección dual y radial; a favor y contrario a las agujas del reloj, hasta alcanzar el punto sur (ver figura 7).

De los diferentes disparos logrados a diferentes ángulos en el transcurso de esta investigación, ninguno logró abrir y volcar por completo el material para formar el borde sur. En el experimento con ángulo de incidencia de 60 grados se puede observar que el material que formaría el borde no logra abrirse hasta volcarse hacia afuera, sino que queda erguido. En los experimentos con ángulos de incidencia de 65,70 y 75 grados, la energía del disparo fue lo suficiente como para dejar un borde norte parecido a una lengua doblada y un pequeño promontorio al sur del cráter. En los experimentos con ángulos de incidencia de 80, 85 y 90, la energía cinética de la componente norte no fue capaz de levantar y volcar el material para formar el borde. Las débiles ondas de expansión solo levantan por un instante el borde que colapsa inmediatamente al interior de la cavidad para después formar lo que he llamado un borde de levantamiento.

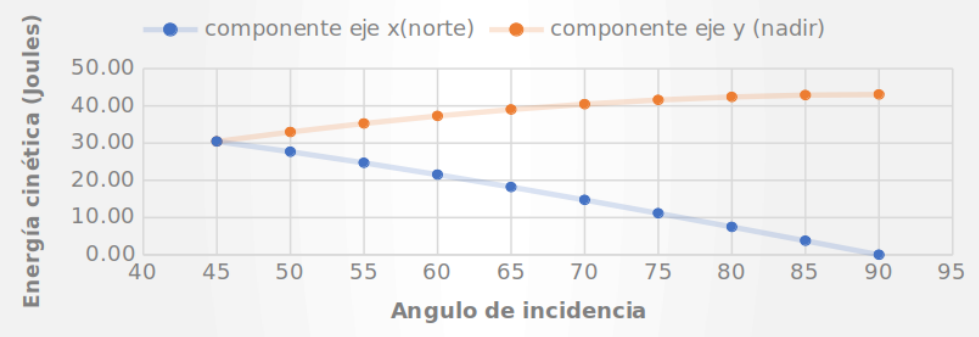

(a) Gráfica que muestra el declive y aumento de la energía cinética de las componentes según el ángulo de incidencia.

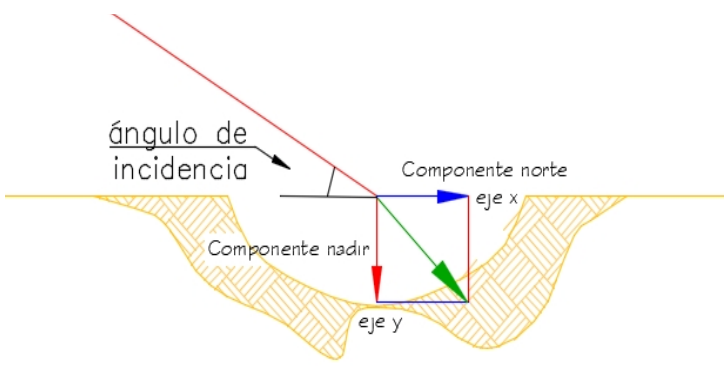

(b) Esquema que muestra la dirección de las componentes de la energía cinética total dividida en dos direcciones según el ángulo de incidencia.

Figura 4: Del gráfico de la figura 4 a podemos visualizar como la componente nadir alcanza la energía total de disparo del rifle a los 90 grados de incidencia de una forma muy gradual. Es decir, de 30.44 a 43.04 Joules. En cambio, la componente norte decae con mayor pendiente de 30.44 a 0.00 Joule con el disparo a un ángulo de incidencia de 90 grados. Imágenes propias.

\subsection{Diámetro, forma y profundidad}

Se observó una disminución en la medida del diámetro N-S según se disparaba de 45 a 90 grados (ver figura 5). La forma del cráter cambió de igual forma. De un cráter elíptico resultado de un ángulo inicial de 45 grados hasta un cráter con forma muy circular conforme se acercaba al ángulo de incidencia de 90 grados. La tendencia son diámetros menores con ángulos de incidencia mayores. 


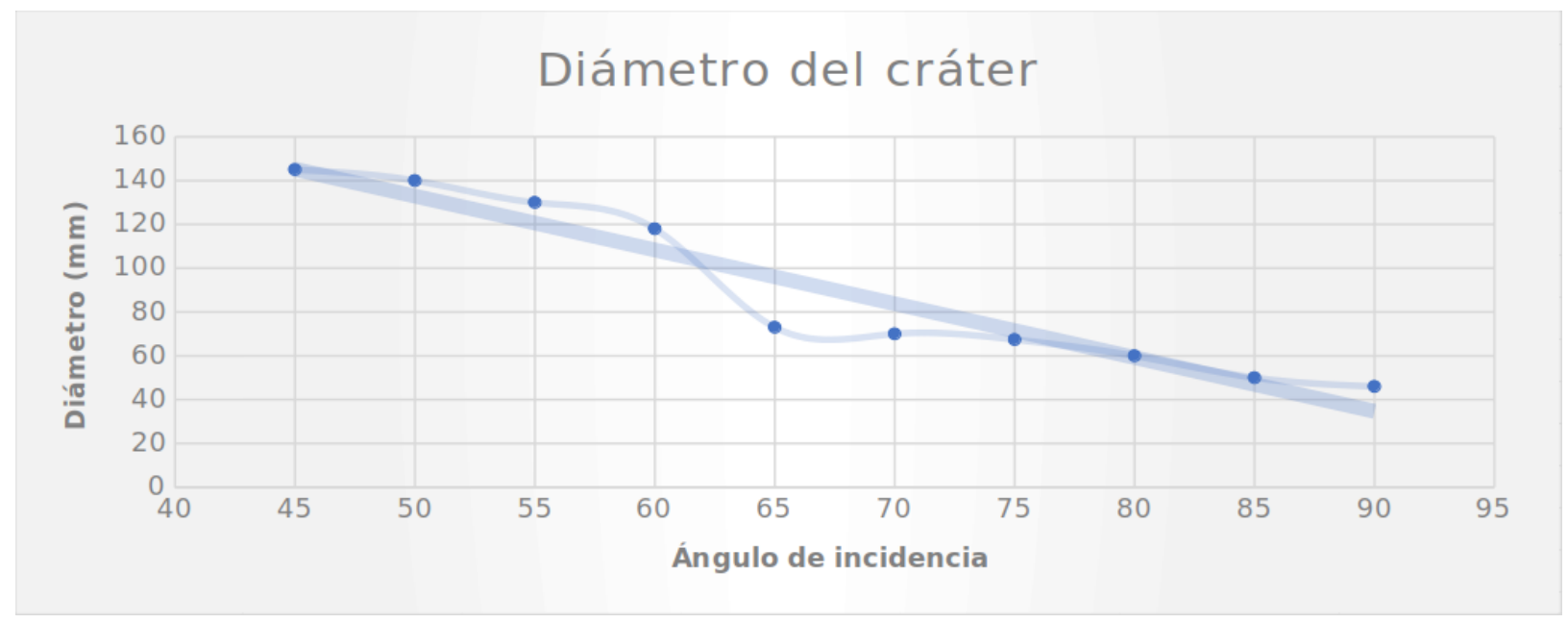

Figura 5: Gráfico que muestra la disminución del diámetro conforme se aumentó el ángulo de incidencia del disparo.

La profundidad medida en los cráteres formados a $45^{\circ}, 50^{\circ}, 55^{\circ}$ y $60^{\circ}$ no varía mucho. Los taludes y profundidad del cráter permanecen estables. El agua ingresa muy lentamente a la cavidad a través de los taludes, lo que provoca una erosión casi imperceptible. La mayoría del material expulsado no vuelve a ingresar a la cavidad. Por tal razón la profundidad se mantiene estable con un valor que osciló de $53 \mathrm{~mm}$ a $60 \mathrm{~mm}$ respectivamente. A partir de los 65 grados las profundidades medidas dejaron de ser estables porque la mayoría del material se desplomaba al interior del cráter. En el gráfico de la figura 6a se observa como a $65^{\circ}$ la profundidad medida cae abruptamente a $27 \mathrm{~mm}$ para luego incrementar a 41 y $34 \mathrm{~mm}$, a $70^{\circ}$ y $75^{\circ}$ respectivamente, hasta conseguir una profundidad promedio de $18.67 \mathrm{~mm}$ para los disparos efectuados con los ángulos de incidencia de $80^{\circ}, 85^{\circ}$ y $90^{\circ}$. Es claro que, con un dispositivo de disparo de mayor poder, los resultados en la profundidad no hubieran variado mucho.

El mecanismo que actuaría sobre la profundidad del cráter de impacto en un pantano es algo más complicado. Se necesita un experimento con condiciones más energéticas y con mayor tiempo de observación para poder deducir que ocurre con la profundidad. Este experimento no puede mostrar los efectos que causa el transcurrir del tiempo. Ni mucho menos que ocurre en un proceso tan gradual de sedimentación como el observado en zonas palustres. Se puede inferir, que lo que puede producir el paso del tiempo en la profundidad de un cráter formado en un pantano, es la disminución de dicha profundidad; producto de la sedimentación gradual pero constante de los depósitos aluviales que vienen desde tierras más altas. 


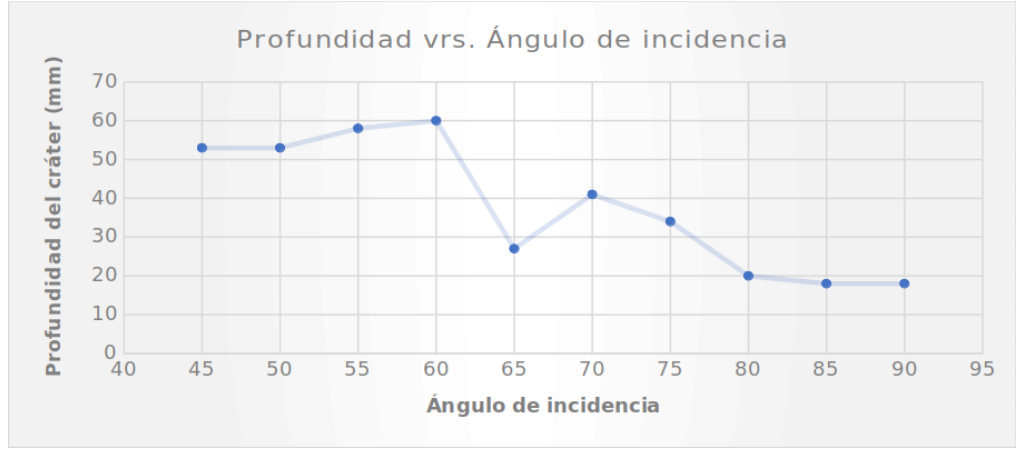

(a)

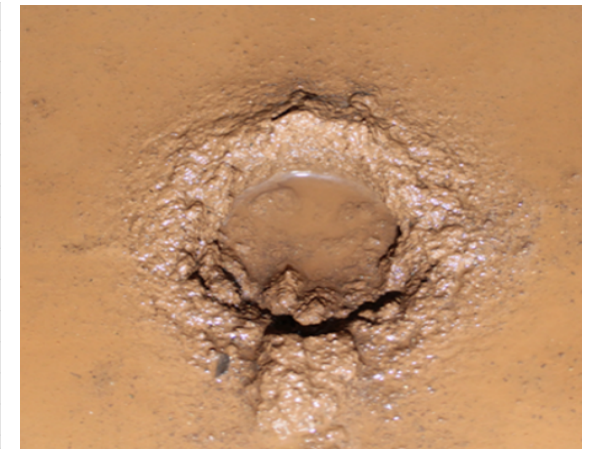

(b)

Figura 6: (a) Gráfico que muestra la variación de la profundidad del cráter a diferentes ángulos de incidencia. (b) Imagen que muestra el cráter que se formó al disparar con ángulo de incidencia de 65 grados, donde se puede apreciar el material que reingresó a la cavidad. Imágenes propias.

\subsection{Características de borde y del eyecta}

El lograr observar la disminución en la elevación y cantidad de material que formaría el borde conforme se incrementaba el ángulo de incidencia fue gracias a la débil energía de impacto. Esto resultó ventajoso a la hora de observar los resultados límites de varios impactos en condiciones de mínima velocidad. Lo más notable fue el poder visualizar como la capa superficial del material expulsado que formaría el borde no logra volcarse por completo al sur del cráter. Es por esta razón que siempre se observó el borde sur más estrecho que el borde norte (ver figura 7). A $45^{\circ}, 50^{\circ}$ y $55^{\circ}$, el borde comienza su apertura al norte y se detiene antes de alcanzar el punto sur. El resultado final es un borde bien desarrollado, pero más estrecho al sur del cráter. A $65^{\circ}, 70^{\circ}$ y $75^{\circ}$ se pudo observar que el material que comienza a volcarse hacia el exterior de la cavidad al norte del cráter se detiene y regresa hacia el interior para formar algo parecido a una lengua doblada. A $80^{\circ}, 85^{\circ}$ y $90^{\circ}$ todo el material que formaría el borde volcado colapsa al interior de la cavidad produciendo un borde de levantamiento. Durante el experimento se pudo observar que conforme incrementamos el ángulo de incidencia la elevación promedio del borde y el volumen total del eyecta se reducen hasta alcanzar valores mínimos.

Las características comunes y relevantes observadas en los cráteres donde el borde queda bien definido y con mayor elevación que la superficie inalterada son:

- El material que se desprende del borde forma promontorios (islotes) de formas variadas, los cuales conservan una mayor elevación que la superficie inalterada, en la periferia del cráter. Los tamaños de las piezas que formarían los promontorios individuales variaron inversamente con su velocidad de eyección. Las piezas más pequeñas se expulsaron primero con las velocidades más altas, y a medida que el cráter incipiente creció en tamaño, las dimensiones de las piezas aumentaron y las velocidades de eyección disminuyeron (Gault y Greeley, 1978).

- Se observan lóbulos de diferentes formas que sobresalen del contorno principal del borde sin una aparente separación.

- El borde sur siempre es más estrecho que el borde norte. Esta característica se puede utilizar como indicador de la dirección de entrada del impactor. 


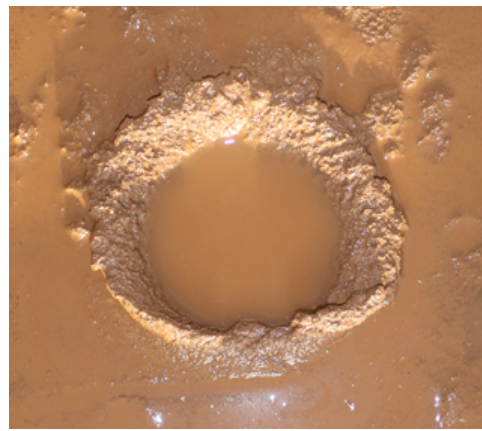

(a) Ángulo de incidencia de $55^{\circ}$

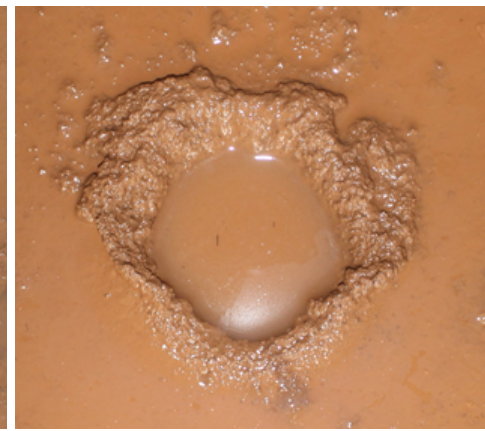

(b) Ángulo de incidencia de $60^{\circ}$

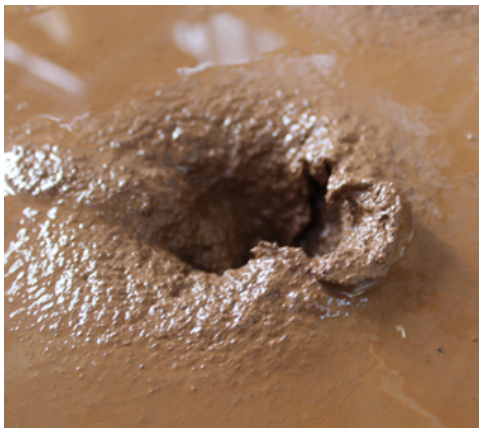

(c) Ángulo de incidencia de $70^{\circ}$

Figura 7: Secuencia de la morfología del borde conforme se incrementaba el ángulo de incidencia. Fotografías propias.

\subsection{Morfología general}

La morfología general que se deriva de esta investigación consiste en las siguientes características:

- Cráter de forma elíptica con borde bien definido con lóbulos o aglutinaciones unidos al contorno circular.

- Promontorios individuales de diferentes formas, con elevaciones mayores a la superficie inalterada.

- Un espejo de agua que deja en evidencia el nivel freático de la zona palustre.

- Cráteres secundarios esparcidos aleatoriamente en la periferia del cráter.

- El borde sur del cráter es más estrecho que el borde norte.

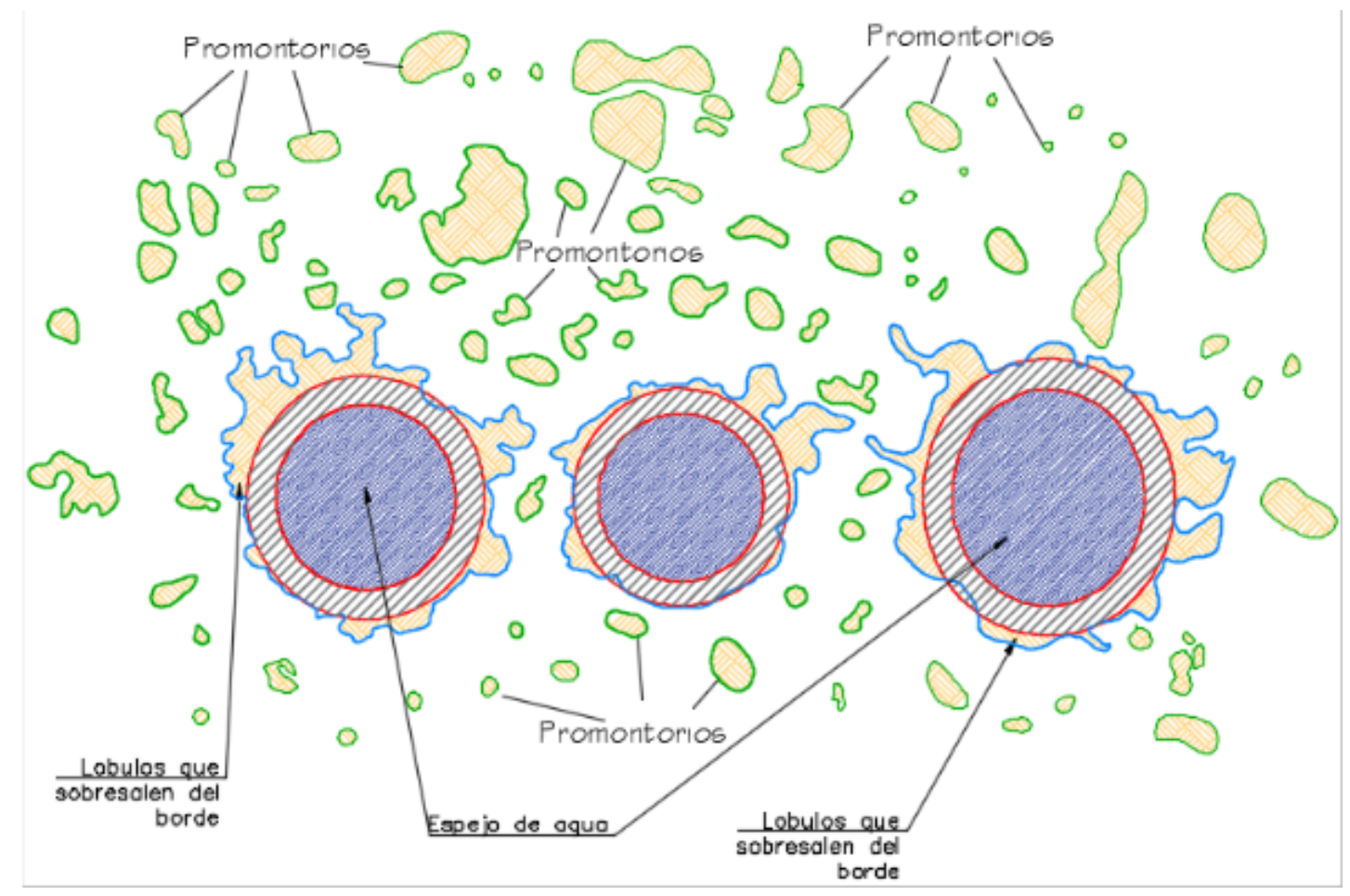

Figura 8: Morfología general esperada de cráteres de impacto en zonas pantanosas. Fuente: figura propia. 


\subsection{Comparación con la laguna Liwa}

\subsubsection{Emplazamiento geologíco de la laguna Liwa}

La Laguna Liwa que tiene un diámetro aproximado de $3.2 \mathrm{~km}$, está ubicada en el Municipio de Puerto Lempira, Departamento de Gracias a Dios, Honduras C.A., a $15^{\circ} 15^{\prime} 06^{\prime \prime}$ latitud norte y $83^{\circ} 34^{\prime} 07^{\prime \prime}$ longitud oeste. Liwa está emplazada en un pantano según hoja cartográfica del Instituto Geográfico Nacional de Honduras. No hay presencia de una superficie rocosa, necesaria para un análisis litológico y mineralógico. Esto debido al enterramiento de capa tras capa de sedimentos típicos de medios palustres provocados por la acumulación de materia orgánica casi exclusivamente de origen vegetal, además de grava, arena, arcilla y limos. La región de la Mosquita Costera fue un sinclinal largo y profundo (Geoclina) durante los tiempos del Mesozoico y Cenozoico, y es una de las cuencas sedimentarias más grandes de América Central. La cuenca se formó por primera vez en Honduras durante los períodos Triásico y Jurásico y la deposición sedimentaria ha continuado casi sin interrupción hasta la actualidad (Mills y Hugh, 1974). La Cuenca sedimentaria de la Mosquitia se encuentra entre el río Patuca y el río Coco (ver figura 9).

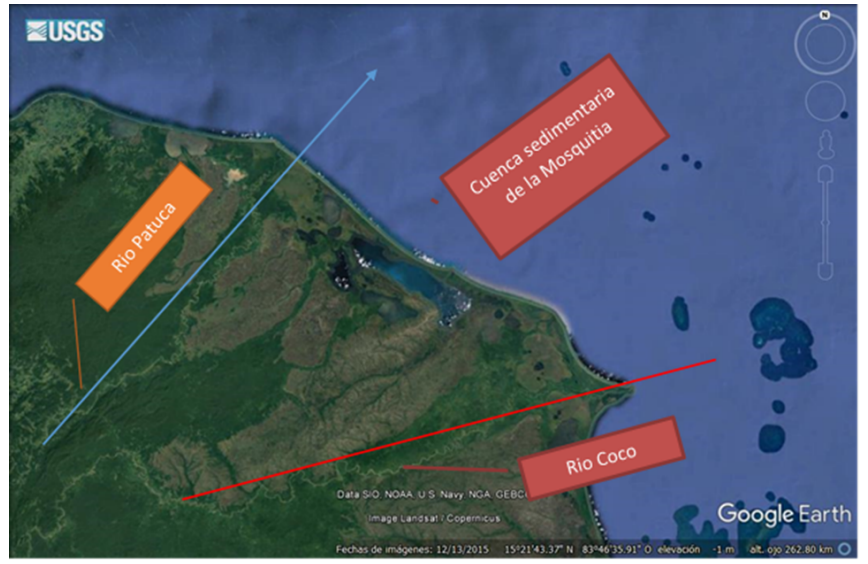

(a) La cuenca sedimentaria de la Mosquitia se encuentra entre el río Patuca y el río Coco.

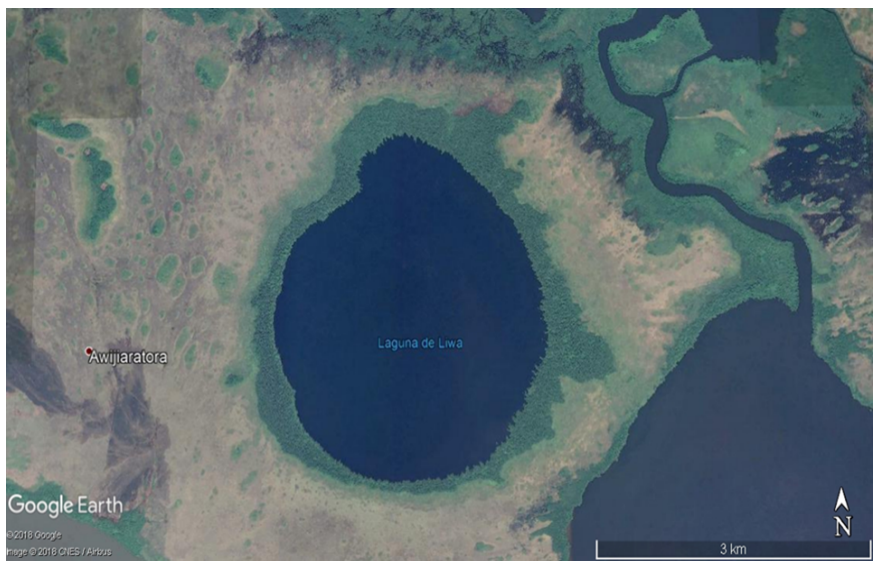

(b) Laguna Liwa

Figura 9: Recuperado de Google Earth, 2018.

Con tasas anuales de precipitación de $2.8-3.4 \mathrm{~m}$ /año (CIDBIMENA, Análisis de los valores promedio de lluvia anual en Honduras por cada departamento, 1966 - 1985), estas tierras bajas representan una de las regiones más húmedas de la Tierra. Las llanuras aluviales de la costa de la Mosquitia se formaron sobre una masa coalescente de arena deltaica y depósitos de grava derivados de la erosión de las tierras altas del interior con dirección hacia el oeste del territorio. Estos depósitos pueden alcanzar un espesor de hasta 4500 metros en algunas áreas (Rogers, 1998).

\subsubsection{Comparación de características fotogeológicas de Liwa con morfología general obtenida me- diante el experimento}

Comparativamente hablando podemos encontrar varias similitudes entre las características observadas en la morfología general obtenida con el experimento de impacto y las características que se observan en la fotografía satelital del área de la Laguna Liwa. A continuación, se detallan: 


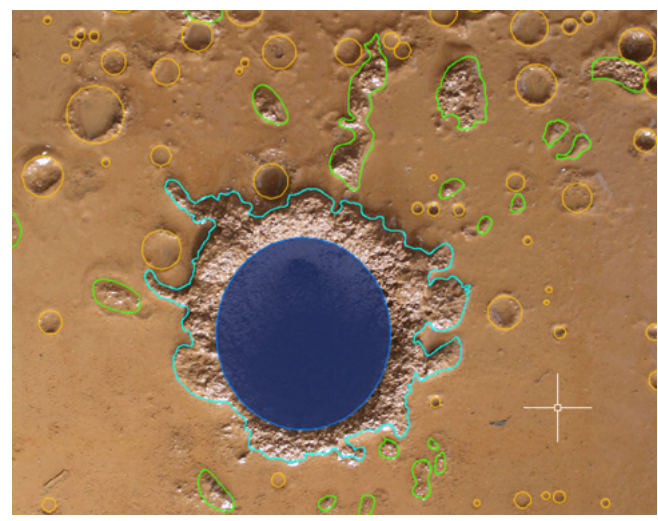

(a) Cráter obtenido a un ángulo de incidencia de $45^{\circ}$. Imagen propia.

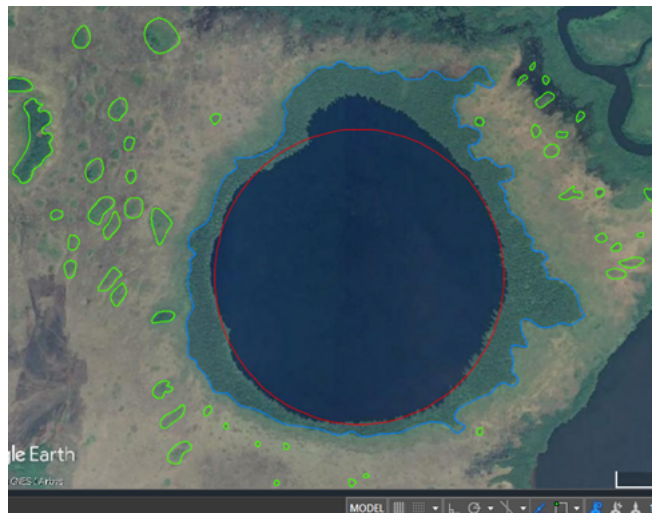

(b) Laguna Liwa. Imagen obtenida de Google Earth.

Figura 10: Comparando similitudes entre las características observadas en la zona de la Laguna Liwa con las características obtenidas mediante el experimento.

- Presencia de un borde con lóbulos que sobresalen del contorno circular. El borde de la Laguna Liwa es hogar de árboles de madera dura de gran altura y no se encuentran en la periferia, solo crecieron en el borde (Mauri, 2017).

- Liwa es casi un circulo perfecto a excepción del lóbulo que exhibe el borde norte.
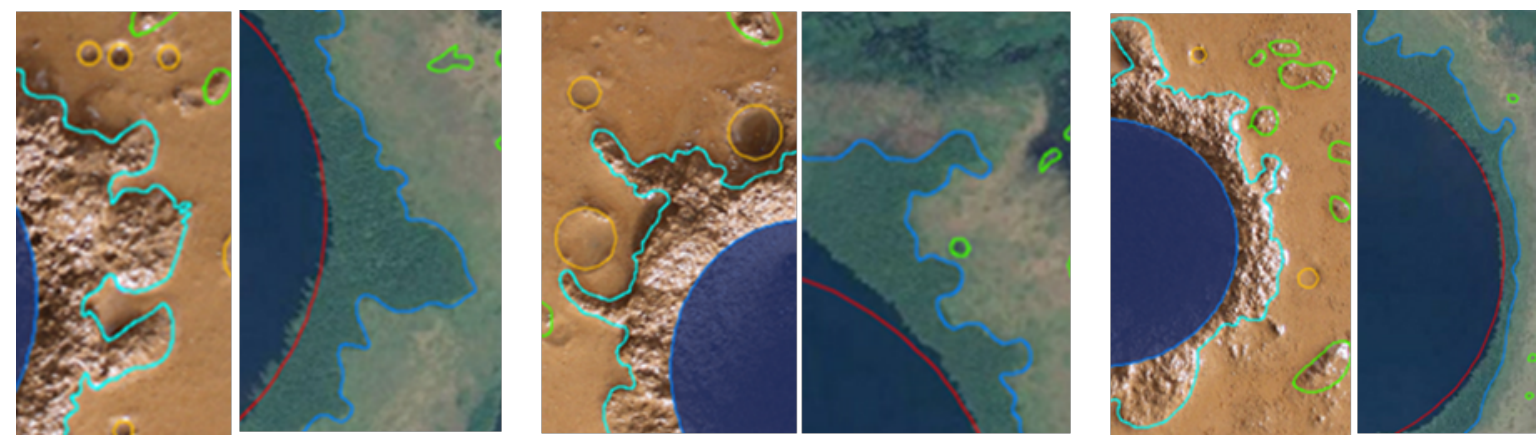

Figura 11: Detalles tanto del borde del cráter resultado del impacto a 45 grados como del borde de la Laguna Liwa. Imágenes propias y adaptadas de Google Earth.

- No se observan rastros de cráteres secundarios en la periferia de la Laguna Liwa. Aunque cabe destacar que no presenta efluentes ni afluentes como el resto de las lagunas.

- Promontorios o islotes de diferentes formas, con elevaciones mayores a la superficie inalterada. En estos promontorios germinó y se desarrolló un tipo de vegetación diferente al resto de la vegetación que presenta la planicie que rodea la laguna (Mauri, 2017). 

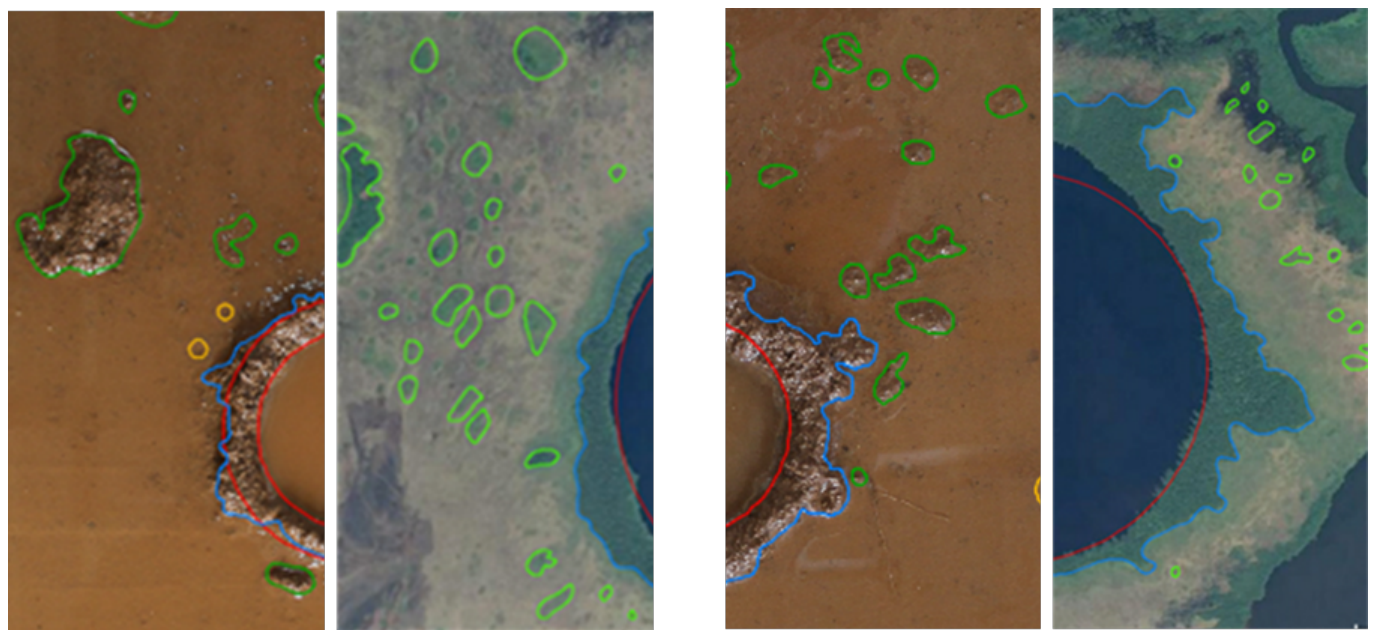

Figura 12: Detalles tanto de los promontorios resultado del impacto a 60 grados como de los promontorios que se observan en la Laguna Liwa. Imágenes propias y adaptadas de Google Earth.

- Se observa en la imagen satelital que el borde sur de la Laguna Liwa es más estrecho que el resto del borde (Ver figura 13).
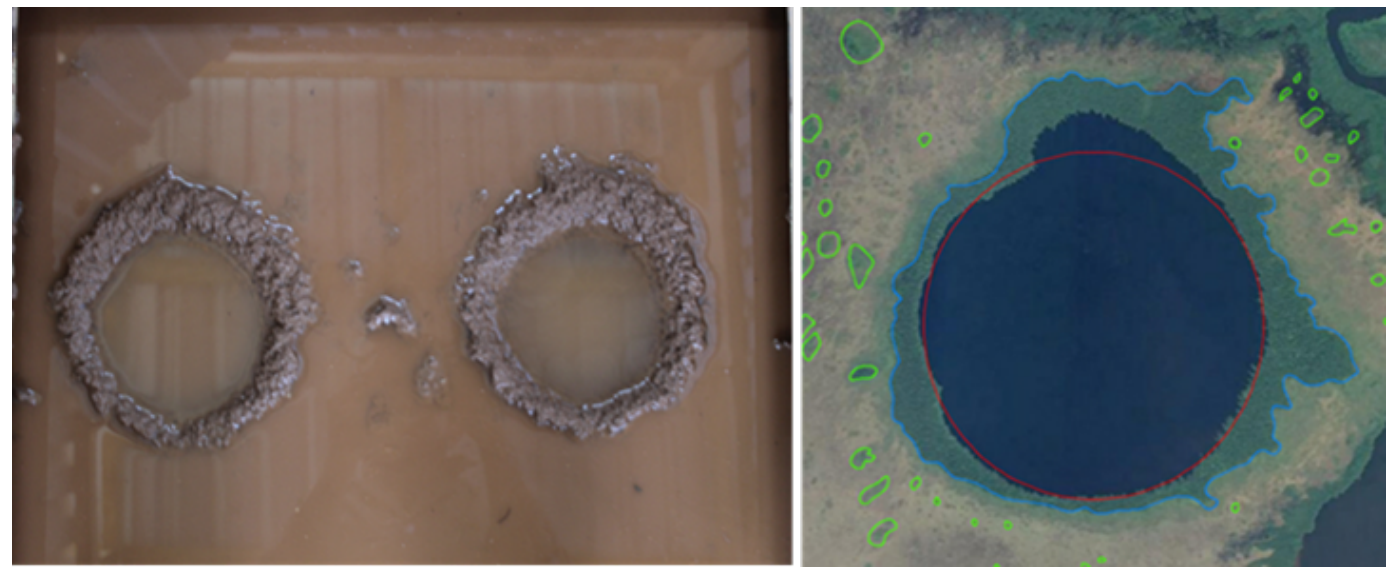

Figura 13: Usando la fotogeología para visualizar la estrechez del borde sur en ambas imágenes. En la imagen de la izquierda se puede observar que la periferia de los cráteres fue inundada para poder visualizar con mayor claridad el ancho de los bordes.

- En la figura 13 se puede observar como el espejo de agua deja en evidencia el nivel freático presente tanto en el material objetivo como en la zona palustre de Liwa.

En el campo de las ciencias planetarias, la fotogeología, o análisis de imágenes, se ha utilizado para buscar la distintiva estructura circular de un cráter de impacto, asimismo de terrazas y picos centrales dentro de los cráteres grandes y complejos (Wright et al., 2013). Varias estructuras de impacto se han encontrado con este método (Folco et al., 2010), (Folco et al., 2011).

Esta técnica fotogeológica por sí sola no puede proporcionar una evidencia definitiva para determinar si es una estructura circular producto del impacto de un asteroide, ya que muchas estructuras circulares pueden estar formadas por otros procesos geológicos como, por ejemplo; las dolinas, formaciones kársticas, diapiros salinos y volcanes (Wright et al., 2013). Es necesario el análisis litológico para la identificación 
de un cráter de impacto; mediante el reconocimiento de una serie de impactitas características y varios efectos producto del metamorfismo de impacto; como por ejemplo los PDFs (Planar Deformation Features), características de deformación planar y la presencia de conos astillados en las rocas afectadas por impacto.

Como resultado del análisis mediante la fotogeología comparativa de la imagen satelital de Liwa y la morfología general obtenida mediante el experimento, surge una hipótesis respecto al proceso de formación de la laguna Liwa. Un proceso que se deriva del impacto de un asteroide en un medio sedimentario palustre el cual se describe a continuación:

Un asteroide de aproximadamente 200 metros de diámetro (diámetro obtenido a partir del diámetro de Liwa y parámetros de densidad tanto del impactor como del objetivo, mediante programa que se encuentra en la página web del siguiente enlace: https://impact.ese.ic.ac.uk/ImpactEarth/ ImpactEffects/) impacta en la planicie de la zona pantanosa de la Mosquitia hondureña, hace un tiempo geológicamente reciente. En la etapa de excavación, durante la cual el cráter transitorio se abre mediante interacciones complejas entre las ondas de choque expansivas y la superficie del suelo original, se produce una expulsión de los sedimentos saturados desde el punto de impacto hacia arriba y hacia afuera, lo que deja una depresión en forma de cuenco (Melosh, 1989). El cráter transitorio se divide en aproximadamente zonas iguales superior e inferior. Durante esta etapa ambas zonas en el cráter transitorio continúan expandiéndose, acompañado por el levantamiento de los sedimentos cercanos a la superficie para formar un borde final con mayor elevación que la zona circundante. Las velocidades impartidas a los sedimentos saturados en la superficie son tan altas como para excavar el material saturado y expulsarlo más allá de este borde (Grieve et al., 1977), (Dence et al., 1977), (Kieffer y Simonds, 1980), (Melosh, 1989). Este material expulsado (eyecta) se desprende de las porciones más cercanas al borde del cráter dando paso a la formación de promontorios aislados de mayor elevación que el resto de la planicie alrededor de la zona externa al borde del cráter. Durante la etapa de modificación final, la depresión en forma de cuenco comienza a llenarse de agua hasta alcanzar el nivel freático de la zona.

Después de ser una planicie muy uniforme, este impacto deja una depresión casi circular, rodeada de un borde con una elevación superior al nivel freático de la zona. Los depósitos aislados también quedan con una elevación superior a este nivel, aunque mucho menor a la elevación del borde.

El resultado son tres zonas de suelo con capacidad de saturación diferente. Por un lado, una planicie que no sufrió alteración durante el impacto, que posee un suelo con nivel de saturación alto a sobresaturado la mayor parte del tiempo. Semillas de especies no acuáticas por lo general no germinan en estos suelos debido a la poca presencia de oxígeno. La falta de oxígeno en suelos sobresaturados afecta el metabolismo respiratorio de la semilla, favoreciendo un metabolismo de fermentación, lo que lleva paulatinamente a la muerte de la semilla (Aravena et al., 2010). La vegetación palustre como el junco logra sobrevivir en suelos de alta saturación con bajos niveles de oxígeno.

Por otro lado, un borde elevado por encima de la planicie que posee un suelo con un grado de saturación nulo a muy bajo, donde semillas de especies arbolíferas no acuáticas de madera dura puedan germinar. Esta situación da lugar a un bosque de madera dura que solo se encuentra en la orilla de la laguna.

Por último, una zona con depósitos aislados (islotes) con grados de saturación medios, donde especies intermedias (entre especies acuáticas y no acuáticas), como la palma de pantano, puede sobrevivir y proliferarse debido a su gran adaptabilidad a suelos arcillosos y encharcados. Este escenario explicaría la diferencia en la vegetación según los niveles finales de la planicie después del impacto. 


\subsection{Comparación de características fotogeológicas de tres cráteres de Marte con la morfología general obtenida}

Los mantos de eyecta que rodean los cráteres de impacto en Marte poseen una morfología "fluidizada" única que se ha atribuido a la influencia de agua o hielo subsuperficial dentro del material objetivo en el momento de la formación del cráter (Head y Roth, 1976), (Carr et al., 1977).

Las imágenes de los orbitadores han proporcionado evidencia fotogeológica convincente de que, en muchos casos, los materiales del eyecta se emplazaron como un flujo de levantamiento del terreno que probablemente se transportó de forma balística desde el cráter y luego se deslizó a lo largo de la superficie del suelo antes de llegar a una posición final de reposo (Gault y Greeley, 1978). Debido a que los cráteres con esta morfología de eyección única no se observan en la Luna o Mercurio, Gault y Greely infieren (como lo sugirió (Carr et al., 1976), (Carr et al., 1977) y (Head y Roth, 1976) que ya sea el agua subsuperficial, el hielo o la atmósfera marciana sean los responsables de los depósitos de eyectas inusuales. En el momento del impacto, la eyección se transformó en una lámina fluidizada, ya sea como resultado del agua acarreada, hielo derretido y vaporizado o gas atmosférico atrapado.

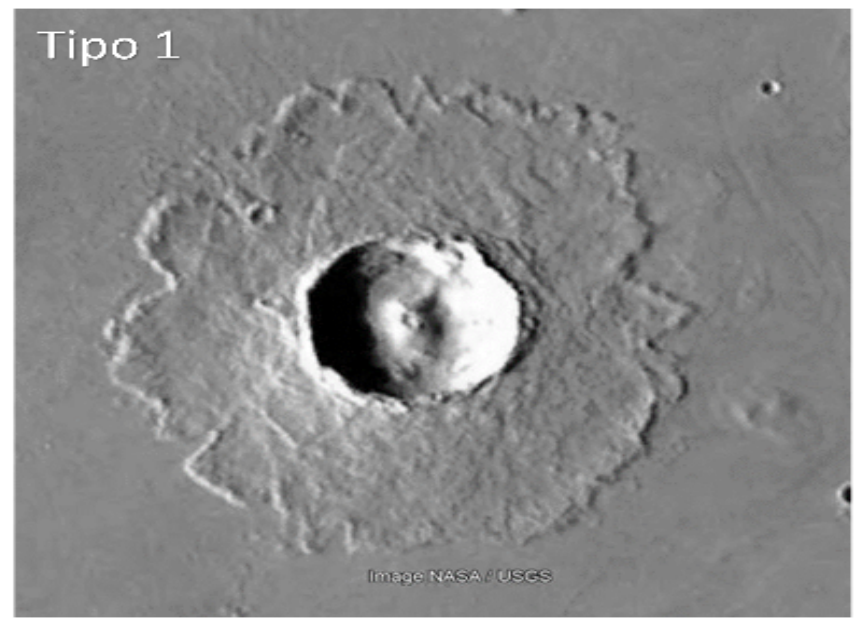

(a) Cráter tipo 1 (Imagen de NASA/USGS)

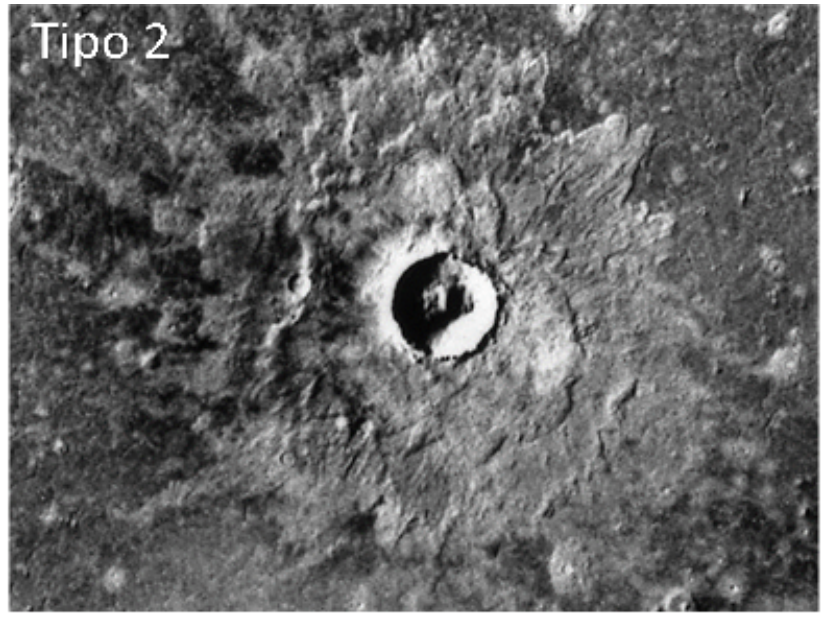

(b) cráter tipo 2 (cuadro del Viking 673B52)

Figura 14: Ejemplo de los dos tipos de cráteres que aparecen frecuentemente en una amplia variedad de latitudes. El cráter tipo 1 posee un solo depósito de eyección continua con terraplen (rampart) distal. El cráter tipo 2 tiene dos faces de eyección que tienen una cresta distal en la unidad externa y un borde convexo en el depósito interno.

Aunque varias morfologías de cráter han sido discutidas por (Mutch y Woronow, 1980) y (Greeley et al., 1980), parece que solo dos tipos de cráteres de eyección fluidizados ocurren con frecuencia en una amplia variedad de latitudes, altitudes y materiales objetivo en Marte (Mouginis-Mark, 1979) (ver figura 13). Los cráteres Tipo 1 poseen un solo depósito de eyección continua (ahora llamados, SLE, single layered eyecta) mientras que los cráteres Tipo 2 están rodeados por dos facies (facies: Conjunto de características de una roca o terreno consideradas desde el punto de vista de su formación.) de eyecciones concéntricas (ahora llamados DLE, double layered eyecta). Ambos tipos de cráteres tienen un depósito de eyección de área extensa que se caracteriza por una cresta distal (o "rampart", término en inglés) y una morfología indicativa de un proceso de flujo en el suelo durante las últimas etapas del emplazamiento (Head y Roth, 1976), (Carr et al., 1977).

Referente a los cráteres con eyecta estratificado (eyecta en dos facies o más) recientemente se han propuesto otros tipos. Los cráteres que se forman en una capa de hielo superficial (ver figura 14) son una 
subclase particularmente inusual, que consiste en cráteres "Perched" (encaramado) (Pr) (Meresse et al., 2006), cráteres de pedestal (Pd) (Fig. 14 c y d) (Kadish y Head, 2011), y más recientemente propuestos, cráteres de eyecta de doble capa (DLE, double-layered eyecta) (Fig.14b) (Weiss y Head, 2013). Algunos de estos cráteres se han clasificado como cráteres de eyección excesiva (EE), que se caracterizan por un volumen de eyección superior a lo que puede caber en la cavidad observada del cráter (Stewart y Black, 2008), (Kadish y Head, 2011), y se interpreta que se forman en un depósito de hielo de decámetros de espesor (Stewart y Black, 2008), (Kadish et al., 2008), (Kadish y Head, 2011), (Meresse et al., 2006), (Weiss y Head, 2013).
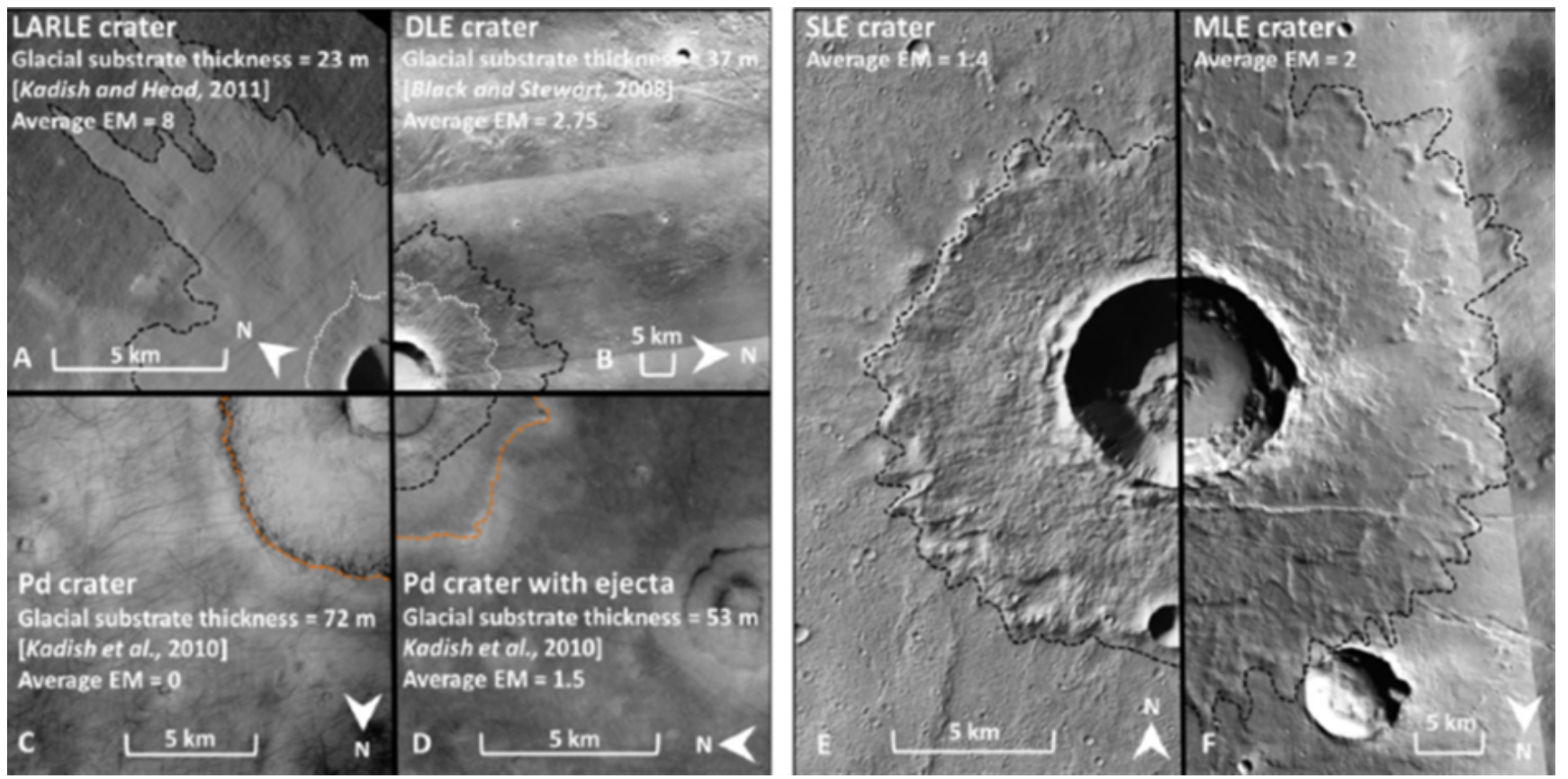

Figura 15: Comparación de seis tipos de cráteres marcianos: (A) LARLE (low-aspect layered ejecta) cráter con una morfología DLE, (B) cráter DLE, (C) cráter Pd, (D) un caso de un cráter PD exhibiendo un depósito de eyecta dentro del pedestal, (E) Cráter SLE, y (F) Cráter MLE (multi layered cráter). La extensión del borde exterior de los depósitos de eyección está marcada por líneas negras discontinuas, la extensión de los depósitos de eyección de la capa interna está marcada por líneas blancas continuas y la extensión del pedestal está marcada por líneas naranjas discontinuas. Coordenadas y números de imagen:(A) 49.1S, 135.7E; CTX image P16_007264_1326,(B) 34.7N, 125.6E; CTX image P17_007554_2154, (C) 55.3N, 91.8E; CTX image G21_026477_2355, (D) 57.2N, 78.5E; CTX image G19_025594_2371, (E) 25.9S, 152.4E; CTX image P22_009821_1533, and (F) 22N, 146E; CTX image P07_003624_2041. (Tomado de:(Weiss y Head, 2014))

Los resultados de un detallado mapeo geológico e interpretación de la naturaleza y las edades relativas y absolutas de las unidades y estructuras en la porción SO de Utopia Planitia $\left(20^{\circ}-45^{\circ} \mathrm{N}, 100^{\circ}-120^{\circ} \mathrm{E}\right)$ propuestos por (Ivanov et al., 2014), sugieren que la mayoría de los cráteres de impacto más grandes (i.e. $>1 \mathrm{~km}$ ) muestran morfologías de eyección (rampart y ejecta tipo panqueque) que son indicativas de la presencia de hielo/agua en los materiales objetivo. Los cráteres con eyecciones similares a panqueques se concentran dentro de la parte central de la cuenca Utopia (a menos de $1000 \mathrm{~km}$ del centro de la cuenca) y los cráteres "Rampart" ocurren en la periferia de la cuenca. Para esta investigación, los tres cráteres candidatos usados para una comparación fotogeológica, se encuentran entre $30^{\circ}-35^{\circ} \mathrm{N}$ y $110^{\circ}-120^{\circ} \mathrm{E}$, que es parte de la porción sur de Utopia Planitia. Estos pertenecen a la categoría de cráteres "Rampart" (como lo establece (Ivanov et al., 2014) con la diferencia de que estos candidatos presentan promontorios que rodean los límites de la cresta distal. Los tres cráteres presentan características muy similares a la morfología general obtenida mediante el experimento. A continuación, se mencionan: 
- Los 3 cráteres marcianos (ver figura 16 y figura 17) tienen una forma elíptica con borde bien definido, con lóbulos o aglutinaciones unidos al contorno del borde.

- Fragmentos discretos que se desprendieron del borde principal para formar promontorios de formas variadas alrededor del eyecta continuo. Promontorios con elevaciones mayores a la superficie inalterada.

- Cráteres secundarios esparcidos aleatoriamente en la periferia del cráter.

- Siguiendo la línea del eje mayor E-O de las elipses se puede observar que hay una mayor y menor anchura respectivamente en los mantos del eyecta.
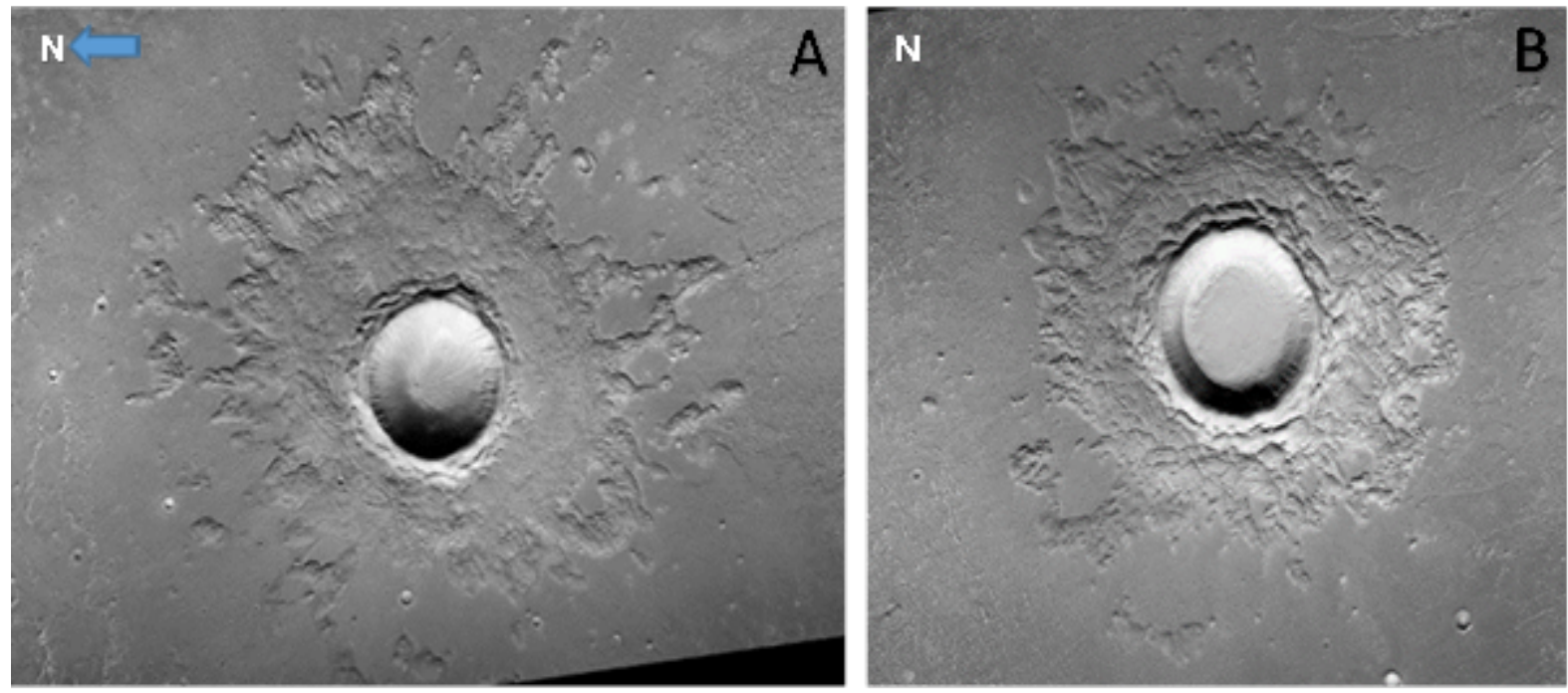

Figura 16: Cráteres ubicados al sur de Utopia Planitia. A) 32.67N, 116.38E; CTX image F23_044898_2139. B) 33.55N, 111.88E; CTX image B18_016745_2127. Imágenes de The Mars Reconnaissance Orbiter (MRO) Context Camera (CTX).

Las características observadas sugieren que, al momento del impacto, el estrato superior del material objetivo estaba saturado con agua/hielo. La presencia de fragmentos discretos en los límites del eyecta continuo es un fuerte indicador de la presencia de agua en su estado líquido. Los resultados experimentales obtenidos por (Gault y Greeley, 1978) arrojan luz sobre el comportamiento de la eyección fluidizada en el ambiente marciano. Y se plantean la incógnita sobre si este tipo de eyección involucra tanto agua subsuperficial o hielo derretido acarreado junto con el eyecta, como gas atmosférico atrapado en la eyección. La comprensión de las conexiones potenciales entre los cráteres de eyección fluidizada y los volátiles del subsuelo es de gran importancia, particularmente dadas las implicaciones astrobiológicas de ubicar el hielo de agua del subsuelo por debajo de la isoterma de derretimiento estacional (Jones et al., 2011).

Los estudios continuos de los cráteres con eyecta fluidizado pueden ayudar a comprender las condiciones climáticas del pasado de Marte. 

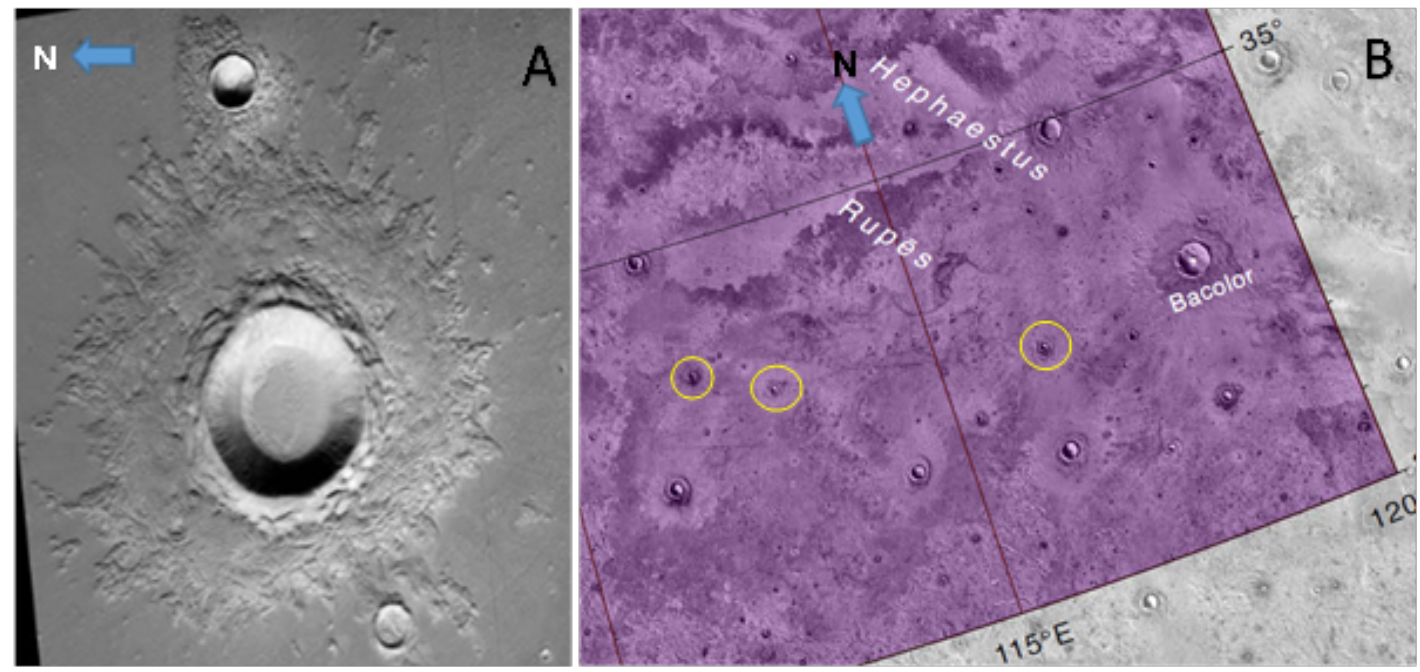

Figura 17: Cráteres ubicados al sur de Utopia Planitia. A) 33.16N, 112.87E; CTX imágen B18_016534_2123 de (MRO) Context Camera (CTX). B) Ubicación de los tres cráteres de impacto en la periferia de Utopia Planitia, delineados en amarillo. Imagen adaptada de THEMIS IR Day Mosaic by ASU.

\section{Conclusiones}

Hay un sinnúmero de características presentes en un pantano como el de la Mosquitia que quedan fuera del presente experimento, tales como el gas natural presente en las capas suprayacentes; la estratificación de base sedimentaria y sus diferentes componentes; la velocidad real de entrada de un asteroide a la atmósfera terrestre entre otras. Es una tarea infructuosa el poder recrear las condiciones reales de un pantano en una simulación de impacto a pequeña escala, sin embargo, se han podido analizar los efectos de un impacto de baja velocidad sobre las características que deja un material objetivo saturado con agua.

Fue posible constatar que gracias a las fuerzas cohesión y adhesión que ejerce el agua sobre el material, que el borde del cráter queda bien definido a tal punto que el agua no reingresa a la cavidad justo después del impacto. El agua ingresa con baja energía a través de los taludes de la cavidad de una forma muy lenta hasta alcanzar nuevamente el nivel freático. El borde si logra mantener una elevación superior a la elevación de la superficie inalterada. Los cráteres que se formaron usando los ángulos de incidencia de 65 a 90 grados no lograron formar un borde debido a la baja energía del dispositivo de disparo.

La profundidad del cráter se mantiene estable durante todo el proceso de inundación, aunque se observan pequeños desprendimientos del material del talud y del borde. Tanto la profundidad como el diámetro del cráter experimentaron una disminución conforme se incrementaba el ángulo de incidencia del impactor. El proceso de sedimentación que se lleva a cabo en una laguna emplazada en un pantano como el de la Mosquitia es un proceso continuo. Lo que produce una disminución de la profundidad del cráter en un periodo de miles de años. Mediante el experimento no fue posible observar tal efecto.

Las características más notables del eyecta son los lóbulos unidos al borde principal y los segmentos discretos que se desprenden del borde para formar promontorios con una mayor elevación a la elevación de la superficie inalterada. Mediante la evaluación cuantitativa del material esparcido en la periferia del cráter es posible definir la dirección de entrada del impactor. En el experimento se pudo observar que el ingreso del impactor en una dirección sur provoca una mayor cantidad de eyecta en la porción norte de la 
periferia del cráter. Mediante la medición del eje mayor de la forma elíptica del cráter también es posible determinar la dirección de entrada. Usando ambos criterios es posible establecer con mayor precisión la dirección de entrada del impactor, como lo observado en los cráteres marcianos que fueron comparados con la morfología general obtenida mediante el experimento.

Según las características observadas al utilizar la fotogeología comparativa y la morfología general obtenida mediante el experimento, la Laguna Liwa puede ser considerada un candidato a cráter de impacto. Es necesario la evidencia litológica para determinar con toda propiedad esta condición. Se recomienda un estudio que involucre la perforación a profundidades de hasta 700 metros para recopilar la estratigrafía de la zona de Liwa.

De ser posible es conveniente el poder desarrollar un dispositivo de disparo con mayor potencia para poder observar las características que dejan los impactos con ángulos de incidencia mayores a 65 grados. Asimismo, las características del eyecta con los ángulos de incidencia más probables. Se recomienda desarrollar una simulación de impactos en pantano estratificado en capas sedimentarias débiles y saturadas que cubren un basamento de roca cristalina sólida. Esto con el propósito de recrear las condiciones reales de estratificación y sedimentación observadas en las llanuras aluviales.

\section{Referencias}

Ahrens, T. y Okeefe, J. (1977). Equations of state and impact-induced shock-wave attenuation on the moon. Impact and Explosion Cratering, 0.

Aravena, J., Mejías, J., y Amiard, V. (2010). Liberación de azúcares desde semillas de lupino: Dañino efecto del exceso de agua en el suelo. Recuperado de: https://nanopdf.com/download/ daino-efecto-del-exceso-de-agua-en-el-suelo_pdf\#. Santiago, Chile.

Carr, M. H., Crumpler, L. S., Cutts, J. A., Greeley, R., Guest, J. E., y Masursky, H. (1977). Martian impact craters and emplacement of ejecta by surface flow. Journal of Geophysical Research (1896-1977), 82(28):40554065.

Carr, M. H., Masursky, H., Baum, W. A., Blasius, K. R., Briggs, G. A., Cutts, J. A., Duxbury, T., Greeley, R., Guest, J. E., Smith, B. A., Soderblom, L. A., Veverka, J., y Wellman, J. B. (1976). Preliminary results from the viking orbiter imaging experiment. Science, 193(4255):766-776.

Christiansen, E. H. y Spilker, B. (2017). Exploring the planets v18.1. Recuperado de: http://www . explanet.info/. This online textbook is open for revision at any time.

Collins, G. S., Melosh, H. J., y Marcus, R. A. (2005). Earth impact effects program: A web-based computer program for calculating the regional environmental consequences of a meteoroid impact on earth. Meteoritics E Planetary Science, 40(6):817-840.

Dence, M. (1965). The extraterrestrial origin of canadian craters. Annals of the New York Academy of Sciences, 123:941-969.

Dence, M., Grieve, R., y Robertson, P. (1977). Terrestrial impact structures - principal characteristics and energy considerations. LPI Contributions, -1:247-275.

Ernstson, K. y Claudin, F. (2018). Ernstson claudin estructuras de impacto-cráteres meteoríticos. Recuperado de: http://estructuras-de-impacto.impact-structures.com/. 
Folco, L., Di Martino, M., El-Barkooky, A., D’Orazio, M., Lethy, A., Urbini, S., Nicolosi, I., Hafez, M., Cordier, C., Van Ginneken, M., Zeoli, A., Radwan, A., El khrepy, S., ElGabry, M., Gomaa, M., Barakat, A., Serra, R., y M, E. (2011). Kamil crater (egypt): Ground truth for small-scale meteorite impacts on earth. Geology, 39:179-182.

Folco, L., Marti, M., El-Barkooky, A., D’Orazio, M., Lethy, A., Urbini, S., Nicolosi, I., Hafez, M., Cordier, C., van Ginneken, M., Zeoli, A., Radwan, A., El khrepy, S., ElGabry, M., Gomaa, M., Barakat, A., Serra, R., y Sharkawi, M. (2010). The kamil crater in egypt. Science, 329.

Gault, D. E. y Greeley, R. (1978). Exploratory experiments of impact craters formed in viscous-liquid targets: Analogs for martian rampart craters? Icarus, 34(3):486-495.

Greeley, R., Fink, J., Snyder, D., Gault, D., Guest, J., y Schultz, P. (1980). Impact cratering in viscous targets - laboratory experiments. Proceedings, 11th Lunar and Planetary Science Conference, 14.

Grieve, R., Dence, M., y Robertson, P. (1977). Cratering processes - as interpreted from the occurrence of impact melts. En Roddy, D., Pepin, R., y Merrill, R., editores, Impact and Explosion Cratering: Planetary and Terrestrial Implications, pp. 791-814.

Head, J. y Roth, R. (1976). Mars Pedestal Crater Escarpments: Evidence for Ejecta-Related Emplacement. En Planetary Cratering Mechanics, volumen 259, p. 50.

Ivanov, M., Hiesinger, H., Erkeling, G., y Reiss, D. (2014). Mud volcanism and morphology of impact craters in utopia planitia on mars: Evidence for the ancient ocean. Icarus, 228:121-140.

Jones, E., Lineweaver, C., y Clarke, J. (2011). An extensive phase space for the potential martian biosphere. Astrobiology, 11:1017-33.

Kadish, S. y Head, J. (2011). Impacts into non-polar ice-rich paleodeposits on mars: Excess ejecta craters, perched craters and pedestal craters as clues to amazonian climate history. Icarus, 215:34-46.

Kadish, S., Head, J., Barlow, N., y Marchant, D. (2008). Martian pedestal craters: Marginal sublimation pits implicate a climate-related formation mechanism. Geophys. Res. Lett, 35.

Kieffer, S. y Simonds, C. (1980). The role of volatiles and lithology in the impact process. Reviews of Geophysics, 18.

Lindström, M., Sturkell, E., Törnberg, R., y Ormouml, J. (1996). The marine impact crater at lockne, central sweden. Gff-Uppsala-, 118:193-206.

Mauri, J. (2017). Identificando posible cráter de impacto en gracias a dios mediante teledetección. Ciencias Espaciales, 10:35.

Melosh, H. (1989). Impact cratering: A geologic process. Research supported by NASA. New York, Oxford University Press (Oxford Monographs on Geology and Geophysics, No. 11), 1989, 253 p.

Meresse, S., Costard, F., Mangold, N., Baratoux, D., y Boyce, J. M. (2006). Martian perched craters and large ejecta volume: Evidence for episodes of deflation in the northern lowlands. Meteoritics $\mathcal{E}$ Planetary Science, 41(10):1647-1658.

Mills, R. y Hugh, K. (1974). Reconnaissance geologic map of mosquitia region, honduras and nicaragua caribbean coast. Am. Assoc. Petrol. Geol. Bull., 58:189-207. 
Mouginis-Mark, P. (1979). Martian fluidized ejecta morphology: Variations with crater size, latitude, and target materials. Journal of Geophysical Research, 84.

Mutch, P. y Woronow, A. (1980). Martian rampart and pedestal craters' ejecta-emplacement: Coprates quadrangle. Icarus, 41:259-268.

Okeefe, J. y Ahrens, T. (1975). Shock effects from a large impact on the moon. Proc. Lunar Sci. Conf., 6.

Okeefe, J. y Ahrens, T. (1977). Impact-induced energy partitioning, melting, and vaporization on terrestrial planets. Proc. Lunar Sci. Conf., 8.

Okeefe, J. y Ahrens, T. (1992). Planetary cratering mechanics. Journal of Geophysical Research Atmospheres, 98.

Ormö, J., Lindström, M., Lepinette, A., Martinez-Frias, J., y Diaz-Martinez, E. (2006). Cratering and modification of wet-target craters: Projectile impact experiments and field observations of the lockne marine-target crater (sweden). Meteoritics \& Planetary Science, 41(10):1605-1612.

Ormö, J. y Oms, O. (2013). La formación de cráteres de impacto. un proceso fundamental en el sistema solar. Revista de la Asociación Española para la Enseñanza de las Ciencias de la Tierra, 21(3):310-320.

Perumal, S. K. y Kring, D. (2008). Impact fracturing and structural modification of sedimentary rocks at meteor crater, arizona. Journal of Geophysical Research Atmospheres, 113.

Roddy, D., Pepin, R., y Merrill, R., editores (1977). Impact and explosion cratering: Planetary and terrestrial implications; Proceedings of the Symposium on Planetary Cratering Mechanics, Flagstaff, Ariz., September 13-17, 1976.

Rogers, R. (1998). Incised meanders of the río patuca, stream piracy and landform development of the la mosquitia, central america. Field Guides and Abstracts: Contributions to Geology, 3:92.

Shoemaker, E. (1962). Physics and astronomy of the moon. Interpretation of lunar craters, pp. 283-359.

Stewart, S. y Black, B. (2008). Excess ejecta craters record episodic ice-rich layers at middle latitudes on mars. Journal of Geophysical Research, 113.

Therriault, A. y Lindström, M. (1995). Planar deformation features in quartz grains from the resurge deposit of the lockne structure, sweden. Meteoritics, 30:700.

Weiss, D. y Head, J. (2014). Ejecta mobility of layered ejecta craters on mars: Assessing the influence of snow and ice deposits. Icarus, 233:131-146.

Weiss, D. K. y Head, J. W. (2013). Formation of double-layered ejecta craters on mars: A glacial substrate model. Geophysical Research Letters, 40(15):3819-3824.

Wright, S. P., Tornabene, L. L., y Ramsey, M. S. (2013). Remote Sensing of Impact Craters, capítulo Thirteen, pp. 194-210. John Wiley \& Sons, Ltd. 